\title{
A neoclassical perspective on Switzerland's 1990s stagnation
}

\author{
Yannic Stucki ${ }^{{ }^{*}}$ (D) and Jacqueline Thomet ${ }^{2}$
}

\begin{abstract}
We study Switzerland's weak growth during the 1990s through the lens of the business cycle accounting framework of Chari et al. (Econometrica 75(3):781-836, 2007). Our main result is that weak productivity growth cannot account for the 1993-1996 stagnation episode. Rather, the stagnation is explained by factors that made labour and investment expensive. We show that increased labour income taxes and financial frictions are plausible causes. Holding these factors constant, the counterfactual annualized real output growth over the 1993Q1-1996Q4 period is 1.93\% compared to realized growth of $0.35 \%$.
\end{abstract}

Keywords: Business cycle accounting, Housing crisis, Stagnation, Switzerland

JEL Classification: E13, E20, E32, E65

\section{Introduction}

Severe economic crises are often followed by a prolonged episode of economic stagnation (see, e.g. Jordà et al., 2013). Understanding the causes of such stagnation episodes is a key task in macroeconomics. As a case study, this paper examines a much under-researched episode: the Swiss stagnation during the 1990s. The Swiss stagnation episode stands out compared to the experience of most other industrialized countries. Although many countries experienced a recession at the beginning of the 1990s, most industrialized countries returned to growth relatively quickly. In contrast, Switzerland remained in a prolonged stagnation that lasted until 1997 (see Fig. 1). Annual real growth averaged approximately $1 \%$ throughout the decade, placing Switzerland second-to-last among all OECD countries. Even Japan, which suffered the socalled "lost decade", grew more strongly. In per-capita terms, the picture for Switzerland is even bleaker, with average annual real growth rates of approximately $0.3 \%$.

Different conjectures about the causes of the 1990s stagnation exist. A possible explanation is the tightening

\footnotetext{
*Correspondence: YStucki@gmx.ch

1 Swiss National Bank, Börsenstrasse 15, 8022 Zürich, Switzerland Full list of author information is available at the end of the article
}

of financial conditions associated with the collapse of the Swiss housing market. This collapse led to losses in the domestic lending business comparable in size to those that occurred in the USA during 2007 and triggered a strong consolidation in the banking sector. ${ }^{1}$ Interestingly, despite the strong movements in financial conditions, the Swiss public and policy debates focused on other explanations. During the 1990s, the policy discussion was dominated by the concern that the lack of competition in the domestic market causes stagnation in productivity growth. More recently, the debate has shifted towards explanations that point to a depression in exports caused by an expensive Swiss franc or an increase in payroll taxes and unemployment benefits acting as work discouragement (see, for instance, Dreher \& Sturm, 2005; Ettlin \& Gaillard, 2001; Kleinewefers Lehner, 2007). ${ }^{2}$

\footnotetext{
${ }^{1}$ Write-offs have been estimated to be 42 billion Swiss Francs, which is over $10 \%$ of Swiss GDP of the year 1996. Approximately one-third of the 625 banks registered in 1990 disappeared until 1996. See Swiss Federal Banking Commission (1997) and Kleinewefers Lehner (2007).

${ }^{2}$ Another conjecture on the cause of weak growth is data mismeasurement, e.g. due to underestimated services and terms of trade improvements. However, mismeasurement seems to explain only a small part. According to estimates by Kohli (2004), growth in the 1990-1996 episode is underestimated by approximately 0.4 percentage points a year. Thus, even if we correct for mismeasurement, growth was very weak.
}

\section{Springer Open}

(C) The Author(s) 2021. Open Access This article is licensed under a Creative Commons Attribution 4.0 International License, which permits use, sharing, adaptation, distribution and reproduction in any medium or format, as long as you give appropriate credit to the original author(s) and the source, provide a link to the Creative Commons licence, and indicate if changes were made. The images or other third party material in this article are included in the article's Creative Commons licence, unless indicated otherwise in a credit line to the material. If material is not included in the article's Creative Commons licence and your intended use is not permitted by statutory regulation or exceeds the permitted use, you will need to obtain permission directly from the copyright holder. To view a copy of this licence, visit http://creativecommons.org/licenses/by/4.0/. 


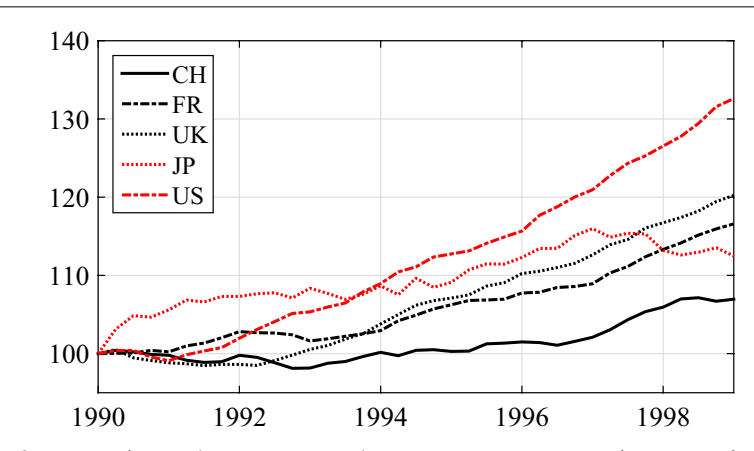

Fig. 1 Real GDP $(1990 Q 1=100)$. Source: OECD Quarterly National Accounts

The goal of this paper is to quantitatively explore these different narratives of the 1990s stagnation. Our focus lies on the 1993-1996 stagnation phase. We do not investigate the preceding boom and recession between 19871992 in detail due to broad consensus on its causes. ${ }^{3}$ In contrast, the reasons for the prolonged stagnation have been discussed much more controversially.

To quantitatively explore the different narratives of the 1990s stagnation, we apply the business cycles accounting (BCA) methodology introduced by Chari et al. (2007) and further explained in the work of Brinca et al. (2016). Our analysis is based on a canonical real business cycle (RBC) model calibrated to data over the 1980Q1-2016Q3 period. Based on this model, the BCA methodology is applied. First, we estimate the deviations from our model's optimality conditions-so-called wedges-that are necessary for the calibrated model to exactly fit the data. As in Chari et al. (2007), we view these wedges as informative about the underlying frictions relevant to understanding particular episodes. Second, we decompose the movement of observed output, investment, and total hours worked into the obtained wedges. Third, we compare the quantitative results to the common narratives of the episode. In particular, we use theoretical mappings of the wedges to different underlying frictions-so-called equivalence results-to explore different conjectures about the causes of the 1990s stagnation.

Overall, the results of our analysis can be summarized as follows. In contrast to the dominant view, we find that a slowdown in productivity growth cannot account for the stagnation. We also find no evidence that a depression in net exports represented an important deterrence to growth. From the perspective of the aggregate data as reflected in the neoclassical growth model, the stagnation is explained by factors that made labour and investment more expensive. Looking for plausible causes, we find that in our episode of interest, approximately $50 \%$ of the labour wedge deterioration can be explained by an increase in labour income taxes, while the investment wedge deterioration can be fully explained by an increase in financial frictions. The effects on growth are sizable: Excluding the measured increase in labour income taxes and financial frictions, we estimate counterfactual annual real output growth of $1.93 \%$ for the years 1993-1996, compared to the observed annual growth of $0.35 \%$.

To our knowledge, this study is the first to assess the different narratives of the 1990s stagnation using microfounded economic models. Several papers look at the Swiss episode in the 1990s within the context of the longterm weakness in growth between 1970 and 2000. Most prominently, Kehoe and Prescott (2002), Kehoe and Ruhl (2003, 2005) apply growth accounting to decompose Swiss output growth into three factors, namely labour input, capital input, and the efficiency with which labour and capital are used. ${ }^{4}$ They identify long-term productivity as a crucial determinant of the weakness in growth. The main difference of our paper compared with their work is our narrow focus on the 1990s stagnation, which brings our attention to shorter-term factors as opposed to trend growth.

Our analysis is also closely related to a vast literature applying BCA to different countries-including Switzerland itself. Of particular interest is Adamek (2011), who uses BCA to look at the Swiss 1990s stagnation. Brinca et al. (2016) include quantitative BCA results for Switzerland in their "Appendix" (without discussion thereof). A key difference between the two papers and our work is that we focus on exploring the different conjectures about the causes of the 1990s stagnation. Additionally, by using new data, their results differ fundamentally from ours. In contrast to our paper, they find evidence in favour of the productivity growth slowdown narrative. The main reason for this difference is that both Adamek (2011) and Brinca et al. (2016) use the OECD hours data. Siegenthaler (2015) shows that the OECD hours data suffer from severe conceptual shortcomings before 1991 . As explained in more detail in the data section, we use an SNB-constructed quarterly hours series that addresses these concerns.

\footnotetext{
${ }^{3}$ In the literature, there is broad consensus that the loose monetary policy stance fuelled the economic boom in the late 1980s and that the sharp increase in the discount rate initiated the burst of the housing bubble and the subsequent recession in the early 1990s. See, e.g. Kleinewefers Lehner (2007) and Weder (2018).
}

\footnotetext{
${ }^{4}$ The authors argue that the Swiss experience over 1970-2000 qualifies as a "Great Depression". As pointed out by Siegenthaler (2015), dubbing it so provoked quite a controversy, as it is in contrast to the public perception of a prosperous and stable economy (see, e.g. Abrahamsen et al., 2005).
} 
Further, there exist a few contributions that use nonmicrofounded economic models to analyse different aspects of the 1990s crisis. Particularly noteworthy is the contribution of Lampart (2006). He does an extensive review on the fiscal and monetary policy decisions during the 1990s and uses a semi-structural Keynesian model to quantitatively assess which role a too restrictive fiscal and monetary policy stance played for the stagnation. A main difference from our work is the scope of the analysis. Our goal is to assess the different aforementioned narratives of the 1990s stagnation, whereas Lampart (2006) focuses on demand effects from government expenditure, tax and monetary policy, and abstracts from supply-sided drivers such as a slowdown in total factor productivity growth.

The remainder of this paper is organized as follows. In the next section, we introduce the prototype model, discuss the data and present the measurement and accounting methodology. Section 3 presents the results. In particular, Sect. 3.3 combines our BCA results with further evidence to assess the different narratives of the episode.

\section{Decomposition methodology}

In this section, we first introduce the neoclassical business cycle model that we use as our lens to analyse the Swiss data. We then describe the estimation and accounting procedures with which we assess the importance of the different wedges for business cycle movements.

\subsection{Model environment}

Our model environment is the same as that in Chari et al. (2007). It is populated by two actors, households and firms. Given an initial per capita capital stock $\ddot{k}_{0}$, the representative household chooses per capita consumption $\ddot{c}_{t}$, per capita investment $\ddot{x}_{t}$, and per capita hours worked $l_{t}$ to maximize lifetime utility

$$
\sum_{t=0}^{\infty} \beta^{t} \mathbb{E}_{0}\left\{\left[\log \ddot{c}_{t}-\psi \frac{l_{t}^{1+v}}{1+v}\right] P_{t}\right\},
$$

subject to the per capita budget constraint and law of motion of capital,

$$
\begin{aligned}
& \ddot{c}_{t}+\ddot{x}_{t} \leq \ddot{w}_{t} l_{t}+r_{t} \ddot{k}_{t}+\ddot{\Omega}_{t}, \\
& P_{t+1} \ddot{k}_{t+1}=\left[(1-\delta) \ddot{k}_{t}+\ddot{x}_{t}\right] P_{t} .
\end{aligned}
$$

Above, $\ddot{w}_{t}$ denotes the wage rate, $r_{t}$ the rental rate on capital, $\ddot{\Omega}_{t}$ per capita lump-sum transfers, and $P_{t}=\left(1+\gamma_{n}\right)^{t} P_{0}$ population, assumed to grow at the deterministic growth rate $\gamma_{n}$. The use of a trema (e.g. $\ddot{w}_{t}$ or $\ddot{k}_{t}$ ) indicates that a variable is growing at the rate of labour-augmenting technology along the balanced-growth path. The use of lower-case letters denotes per capita variables, e.g. $P_{t} \ddot{k}_{t}=\ddot{K}_{t}$ or $P_{t} l_{t}=L_{t}$. The parameters $\beta, v, \psi$, and $\delta$ denote the household discount rate of future utility, the inverse Frisch elasticity of labour supply, a preference parameter for leisure, and the depreciation rate of capital. Optimal behaviour of the representative household leads to

$$
\begin{aligned}
& \psi l_{t}^{\nu} \ddot{c}_{t}=\ddot{w}_{t}, \\
& \frac{1}{\ddot{c}_{t}}=\beta \mathbb{E}_{t}\left[\frac{1}{\ddot{c}_{t+1}}\left(r_{t+1}+1-\delta\right)\right] .
\end{aligned}
$$

Equation (2.1) reflects the optimal labour supply schedule of the household. It states that at optimum, the marginal rate of substitution (MRS) between consumption and leisure is equal to the real wage. Equation (2.2) is the standard Euler equation describing the optimal consumption versus savings decision.

As to the firm side, the representative firm is assumed to rent capital and labour from perfectly competitive markets to maximize profits subject to a Cobb-Douglas production function,

$$
\begin{aligned}
& \max _{L_{t}, \ddot{K}_{t}} \ddot{Y}_{t}-\ddot{w}_{t} L_{t}-r_{t} \ddot{K}_{t}, \\
& \text { s.t. } \quad \ddot{Y}_{t}=\ddot{K}_{t}^{\alpha}\left(Z_{t} L_{t}\right)^{1-\alpha},
\end{aligned}
$$

where $\ddot{Y}_{t}$ denotes aggregate production. We assume that labour-augmenting technology $Z_{t}=\left(1+\gamma_{z}\right)^{t} Z_{0}$ follows a deterministic process and grows at rate $\gamma_{z}$. Profit maximization implies that rental rates equal the respective marginal products

$$
\begin{aligned}
r_{t} & =\alpha \frac{\ddot{Y}_{t}}{\ddot{K}_{t}}, \\
\ddot{w}_{t} & =(1-\alpha) \frac{\ddot{Y}_{t}}{L_{t}} .
\end{aligned}
$$

Finally, market clearing implies that

$$
P_{t}\left(\ddot{c}_{t}+\ddot{x}_{t}\right)=P_{t} \ddot{y}_{t} .
$$

To obtain a stationary model, we detrend all variables that grow on the balanced growth path by the labour-augmenting technology. Below, letters without a trema are used to denote detrended variables (e.g. $\left.c_{t}=\ddot{c}_{t} /\left(1+\gamma_{z}\right)^{t}\right)$. Overall, the equilibrium of our prototype economy is summarized by the following system of equations:

$$
y_{t}=k_{t}^{\alpha} l_{t}^{1-\alpha},
$$




$$
\begin{aligned}
& \psi\left(l_{t}\right)^{v}=(1-\alpha) \frac{y_{t} / c_{t}}{l_{t}}, \\
& \frac{1}{c_{t}}=\beta\left(1+\gamma_{z}\right) \mathbb{E}_{t}\left[\frac{1}{c_{t+1}}\left(\alpha \frac{y_{t+1}}{k_{t+1}}+(1-\delta)\right)\right], \\
& c_{t}+x_{t}=y_{t}, \\
& \left(1+\gamma_{n}\right)\left(1+\gamma_{z}\right) k_{t+1}=(1-\delta) k_{t}+x_{t} .
\end{aligned}
$$

\subsection{Prototype}

In the data, equilibrium conditions (2.3)-(2.6) generally do not hold exactly. The difference between the data and the equilibrium conditions gives rise to four deviations, which we refer to as wedges: time-varying productivity $A_{t}$ (using the terminology of Chari et al. (2007), we refer to it as an efficiency wedge), time-varying taxes on labour income $\left(1-\tau_{l, t}\right)$ (labour wedge), time-varying taxes on investment $\left(1+\tau_{x, t}\right)$ (investment wedge), and government expenditures $g_{t}$ (government wedge). Introducing these four wedges, we rewrite conditions (2.3)-(2.6) as: ${ }^{., 6}$

$$
\begin{aligned}
y_{t}= & \mathbf{A}_{\mathbf{t}} k_{t}^{\alpha} l_{t}^{1-\alpha}, \\
\psi l_{t}^{v}= & \left(\mathbf{1}-\boldsymbol{\tau}_{\boldsymbol{l}, t}\right)(1-\alpha) \frac{y_{t} / c_{t}}{l_{t}}, \\
\frac{1}{c_{t}}= & \frac{\mathbf{1}}{\left(\mathbf{1}+\boldsymbol{\tau}_{x, t}\right)} \beta\left(1+\gamma_{z}\right) \mathbb{E}_{t}\left[\frac { 1 } { c _ { t + 1 } } \left(\alpha \frac{y_{t+1}}{k_{t+1}} \ldots\right.\right. \\
& \left.\left.+\left(\mathbf{1}+\boldsymbol{\tau}_{\boldsymbol{x}, \boldsymbol{t}+\mathbf{1}}\right)(1-\delta)\right)\right], \\
c_{t}+ & x_{t}+\mathbf{g}_{\mathbf{t}}=y_{t} .
\end{aligned}
$$

Note that in principle, there are different ways to enter the wedges into equilibrium conditions (2.3)-(2.6). In the above, the way the labour wedge enters the household time-allocation decision (2.9) is equivalent to a tax on labour income, so we write it as $\left(1-\tau_{l, t}\right)$. For the consumption/investment allocation decision in (2.10), we follow Chari et al. (2007) and enter the wedge as an implicit investment tax, which is useful as it makes it particularly easy to interpret the sign. It also needs to be stressed that at a mechanical level, the wedges represent deviations of the model's equilibrium equations from the data. For instance, Eq. (2.8) implies that all deviations between observed production and implied production (by

\footnotetext{
${ }^{5}$ No wedge enters Eq. (2.7), as we use the equation as an identity to recover a capital stock series based on the observed measures of $x_{t}$ (for a given $k_{0}$ ).

6 We assume that per capita government expenditures follow the same trend as per capita consumption, investment, and production.
}

the Cobb-Douglas function) are translated into movements in the efficiency wedge. Similarly, Eq. (2.9) states that deviations between (1) the MRS between consumption and leisure and (2) the marginal product of labour are translated into the labour wedge. Equations (2.10) and (2.11) state that the investment wedge captures deviations from the optimal saving-consumption decision and that the implicit government expenditures, $g_{t}$, capture differences between the supply of goods and the demand for consumption and investment goods. However, it is not this mechanical interpretation of wedges that we are ultimately after. Rather, our interest lies in the underlying frictions that are captured by the various wedges. We will expand on this point further in Sect. 3.3, when explaining how we use the equivalence result by Chari et al. (2007) to link the wedges to candidate explanations of the 1990s recession and assess their plausibility.

\subsection{Estimation methodology}

\subsubsection{Data}

Measuring the 4 specified wedges requires data on four series: output, consumption, investment, and total hours (the latter consisting of hours per employee times the employment rate). The analysis is conducted at a quarterly frequency, and the overall period considered is 1980Q1-2016Q3.

Data on output, consumption, and investment are obtained from the Swiss State Secretariat for Economic Affairs (SECO). For our purposes, investment corresponds to gross fixed capital formation, and consumption corresponds to final private consumption expenditures. ${ }^{7}$ To ensure the consistency of the data with the structure of our model economy, we make two adjustments. First, since our model does not contain consumption taxes, output and consumption are adjusted for sales taxes. Second, the nominal measures of GDP and its components are expressed in per capita terms using the population aged 16-64 and deflated by both, the implicit GDP price deflator and constant labour-augmenting technological progress. The rate of constant labour-augmenting technological progress is obtained by estimating a linear least-squares trend. We define government consumption, $g_{t}$, as the difference between our adjusted measures of output, consumption, and investment. As we work in a closed-economy model, $g_{t}$ includes net exports. Overall, the data processing closely follows Brinca et al. (2016) with a few adjustments. We provide further details in the

\footnotetext{
${ }^{7}$ In their analysis of Switzerland, Chari et al. (2007) and Brinca et al. (2016) use gross capital formation (GCF) as a measure of investment. We use gross fixed capital formation (GFCF) instead because in Swiss data, all estimation errors are included in inventory changes, causing GCF to be excessively volatile.
} 
(a) Output, investment and consumption

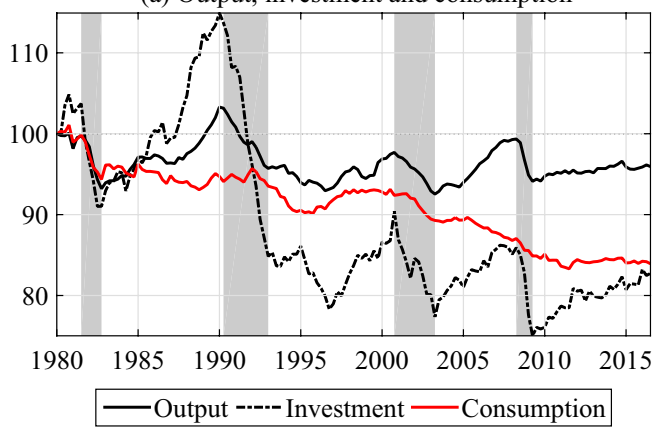

(b) Aggregate hours (as \% of productive time)

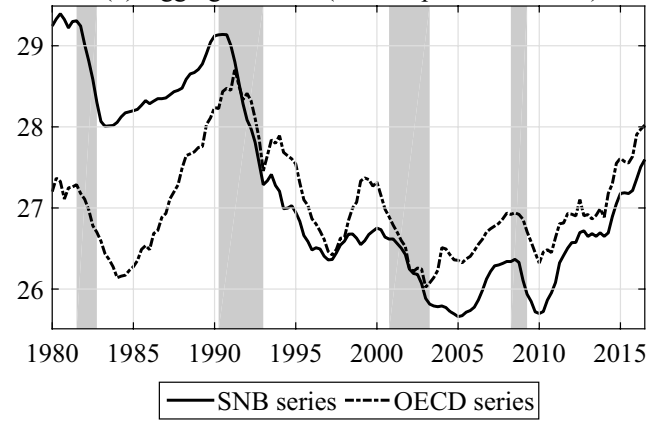

Fig. 2 Model-consistent data (1980Q1-2016Q3)

"Appendix". In the remainder of the text, we refer to our adjusted data as model-consistent data.

Figure 2a shows our model-consistent measures of output (solid black line), consumption (solid red line), and investment (dashed black line). In this and following figures, the data are normalized to equal 100 in the starting period. The shaded areas indicate four important Swiss recession episodes. The figure shows that per capita output remains at approximately 100 over the sample period considered (a consequence of our data treatment), while per capita consumption and investment both have a downward trend. These observations imply that government consumption and net exports have been growing over time-which can be attributed mainly to growth in the trade balance. Another interesting observation in Fig. 2a is the large increase in per capita investment at the end of the 1980s and its subsequent sharp drop. At the height of the investment boom, construction spending amounted to $13.4 \%$ of GDP (approximately 5 percentage points higher than the values that have been observed since 2000).

Regarding data on labour (hours per employee and the employment rate), obtaining series of sufficient quality represents a key difficulty in any empirical work on Switzerland. Problems surrounding the measurement of total hours have been highlighted in the discussion on Switzerland's comparatively low growth observed after 1970. For instance, Siegenthaler (2015) raises the concern that prior to 1991, the OECD series on hours worked per employee do not take absences from work and paid vacation into account. ${ }^{8}$ Exploiting available historical data on the different components of total hours worked, Siegenthaler (2015) establishes a consistent annual time

\footnotetext{
${ }^{8}$ We follow Siegenthaler (2015) and label the hours worked per employee data published by the OECD as the "OECD time series" because the OECD itself combines different Swiss data sources to construct the long time series on hours worked in Switzerland. Details are described in the annual publications of the OECD employment outlook.
}

series of total hours worked for Switzerland covering the 1950-2010 period. In this work, we use a similarly constructed (unpublished) quarterly data series by the Swiss National Bank. ${ }^{9}$ The OECD and SNB series are depicted in Fig. 2b. In the figure, the data are measured as a percentage of productive time (assumed at 1300 hours per quarter). The visual comparison of the SNB (solid black line) and OECD (dashed black line) series shows substantial discrepancies, especially prior to 1991. Compared to the SNB series, the OECD series overstates growth in aggregate hours worked during the 1980s.

Table 1 summarizes the basic descriptive statistics of the cyclical components of our model-consistent data, namely the relative volatility of the series compared to output as well as the cross-correlation patterns of each series with output. What stands out is the large volatility of government consumption compared to output. This high volatility is explained by both the large volatility in the trade balance and the fact that this measure encompasses all statistical errors in the quarterly measurement of GDP.

\subsubsection{Parametrization and calibration}

There are 7 model parameters: the capital share $\alpha$, the discount factor $\beta$, the growth rate of technology $\gamma_{z}$, the growth rate of the population $\gamma_{n}$, the depreciation rate $\delta$, the inverse Frisch elasticity of labour $v$, and the timeallocation parameter $\psi$. Five parameters are set according to Swiss data: We compute capital and labour shares from quarterly Swiss data based on the income approach and obtain an $\alpha$ of $0.32 .{ }^{10} \beta$ is set to 0.9926 , which implies

\footnotetext{
${ }^{9}$ We wish to thank Christian Hepenstrick for kindly making these data available to us.

${ }^{10}$ More specifically, we attribute compensation of employees to labour income. Fixed capital consumption, production charges, and import charges are attributed to capital income. We leave the remainder as ambiguous. The labour share is then obtained as unambiguous labour income divided by GDP net of the ambiguous categories. As earlier data are not available, these computations are based on the 1990-2016 period.
} 
Table 1 Descriptive statistics of model-consistent data (1980Q1-2016Q3)

\begin{tabular}{|c|c|c|c|c|c|c|}
\hline \multirow[t]{2}{*}{$D_{t}$} & \multirow[t]{2}{*}{$\sigma\left(D_{t}\right) / \sigma\left(y_{t}\right)$} & \multicolumn{5}{|c|}{$\operatorname{Corr}\left(D_{t+k}, y_{t}\right)$} \\
\hline & & $k=-2$ & $k=-1$ & $k=0$ & $k=1$ & $k=2$ \\
\hline Consumption $c_{t}$ & 0.60 & 0.44 & 0.52 & 0.55 & 0.44 & 0.33 \\
\hline Investment $x_{t}$ & 2.47 & 0.66 & 0.75 & 0.80 & 0.73 & 0.57 \\
\hline $\begin{array}{l}\text { Government expend. and net } \\
\text { exports } g_{t}\end{array}$ & 3.53 & 0.12 & 0.30 & 0.44 & 0.44 & 0.39 \\
\hline Hours worked $h_{t}$ & 0.61 & 0.51 & 0.68 & 0.81 & 0.86 & 0.82 \\
\hline
\end{tabular}

Data are HP-filtered with $\lambda=1600$

an annual riskless rate of $3 \%{ }^{11} \gamma_{z}$ and $\gamma_{n}$ are estimated as least-square trends from our model-consistent data, with technology growing by $1.10 \%$ and population growing by $0.70 \%$ per year. The time-allocation parameter $\psi$ is set to 9.51, implying a steady-state labour wedge of approximately $40 \%$, which is double the wedge implied by effective taxes. For the remaining two parameters, data of sufficient quality are not available. We follow Brinca et al. (2016) and set $\delta$ such that an annual deprecation rate of $5 \%$ is implied. We set the inverse Frisch elasticity of labour $v$ to 1 in our baseline calibration, but the parameter is subject to several robustness exercises given the controversy over what its correct size may be. The robustness exercises are presented the "Appendix".

\subsubsection{Estimation of the wedges}

It follows from Eqs. (2.8), (2.9) and (2.11) that three wedges (namely the efficiency, labour, and government expenditure wedges) can be directly measured from the data. By contrast, recovering the investment wedge requires estimating the model's decision rules, as its expression in (2.10) involves expectations. The solution hence depends on the exact specification of the model's underlying stochastic process.

We follow Chari et al. (2007) and assume that the wedges are driven by an exogenous four-dimensional random variable, which is called the state $s^{t}$ and has probability $\pi_{t}\left(s^{t}\right)$. The state $s^{t}$ is the history of all underlying events $s_{t}$. The state $s^{t}$ is assumed to follow a Markov process of the form $\pi\left(s_{t} \mid s_{t-1}\right)$. The mapping between the wedges and the event $s_{t}=\left(s_{A, t}, s_{g, t}, s_{l, t}, s_{x, t}\right)$ is one to one; thus, without loss of generality, we have $\quad s_{A, t}=\log A_{t}, s_{g, t}=\log g_{t}, s_{l, t}=1-\tau_{l, t} \quad$ and $s_{x, t}=\left(1+\tau_{x, t}\right)^{-1}$. We uncover the state in two steps. First, we use a maximum likelihood procedure to estimate the parameters of the Markov process, $\pi\left(s_{t} \mid s_{t-1}\right)$. Second, we use the parameters to uncover the realized events $s_{t}$.

\footnotetext{
${ }^{11}$ If tax-free riskless bonds are introduced to the prototype, the ensuing riskless rate is in line with the average real yields on 1-year Swiss Confederation bonds between 1989 and 2007.
}

As to our first step-the estimation of parameters-we specify a VAR(1) process for the events $s_{t}$, namely

$$
s_{t+1}=P_{0}+P s_{t}+\varepsilon_{t+1}, \quad \varepsilon_{t+1} \sim N\left(0, Q Q^{\prime}\right)
$$

where the shock term $\varepsilon_{t+1}$ is iid and normally distributed with mean zero and covariance matrix $Q Q^{\prime}$. We then take a linear approximation of our model around the steady state to obtain linear decision rules and solve the linear model to obtain a state-space representation of the joint dynamics of the aggregates with Klein's (2000) method. As in Chari et al. (2007), we use the steady-state Kalman filter to compute the likelihood function of our model for a given set of parameters. Maximum-likelihood estimates of the parameters $P_{0}, P$, and $Q$ are then obtained based on the unconstrained maximization algorithm of Chari et al. (2007).

As to our second step-the measurement of realized wedges - the decision rules of our linearized model are transformed such that we can uncover the realized events $s_{t}$ from the data on output, consumption, investment, and total hours. The capital stock is recovered by the perpetual inventory method based on the assumption that it is in steady state in 1980Q1.

\subsection{The accounting procedure}

The goal of the accounting step is to isolate the marginal effect of each wedge on the aggregate variables through counterfactual experiments. To give an illustrative example, the following explains how we obtain the marginal effect of the labour wedge on output. The first step is to build a counterfactual economy, referred to as the labour-wedge-alone economy. It reflects a variant of the prototype in which only the labour wedge varies over time, while all other wedges are fixed at their steady-state values. The underlying state $s^{t}$ in this economy is the same as in the prototype economy. Importantly, the mapping between the efficiency, investment, and government expenditure wedges to state $s^{t}$ is set to constants. This is key; because the different states $s^{t}$ and hence wedges are correlated both contemporaneously and across time, we need to keep the same underlying state $s^{t}$ to ensure 
that the expected future realizations of the labour wedge remain the same as in the prototype economy. The next step is to feed the initial capital stock and the identified series of events $s_{t}$ into the labour-wedge-alone model to generate a counterfactual output series called the labour component of output. Now, we obtain the marginal effect of the labour wedge as the difference between actual output and the labour component of output.

For the assessment of different narratives in Sect. 3.3, we are interested in the marginal effect of, say, effective taxes on output. To compute this effect, we apply the logic of the accounting procedure described above. First, we use data on effective taxes to compute the tax-induced wedges, i.e. the counterfactual paths of the wedges that result because of effective taxes only. Second, we compute the counterfactual path of output by feeding the taxinduced wedges into their corresponding wedge-alone economy. ${ }^{12}$

\section{Results}

We now describe our quantitative results from applying the BCA procedure to Swiss cyclical fluctuations, starting with a description of the wedges over the entire 1980-2016 period. We then focus on their role for our target period 1987-1996 and use these results together with additional evidence to assess the different hypotheses of the stagnation. The results for other values of the Frisch elasticity $v$ are discussed in the "Appendix" and are similar.

\subsection{Properties of the wedges over the 1980-2016 period}

Figure 3 shows the evolution of the wedges over our full sample period (1980Q1-2016Q3), which allows for a better perspective of the 1990s recession within the context of Swiss business cycles. More precisely, the figure shows the evolution of detrended output (solid black line) along with the evolution of the efficiency (dashed black), labour (dashed red), investment (dash-dotted red), and the government (dotted red) wedges. The figure shows that the underlying distortions revealed by the four wedges have different patterns. Over the entire sample period, the figure depicts structurally worsening labour and investment wedges and a structurally improving efficiency wedge. Also of note is the relatively strong comovement between the efficiency wedge and output. The figure also depicts a positive comovement between output and both the

\footnotetext{
12 To give an example, consider the marginal effect of payroll taxes on output. In our model, payroll taxes affect only the labour wedge. We hence start by computing the payroll-tax-induced labour wedge. We then feed the payrolltax-induced labour wedge into the labour-wedge-alone economy to compute a counterfactual path of output. The marginal effect of payroll taxes then corresponds to the difference between actual output and the estimated payrollcomponent of output.
}

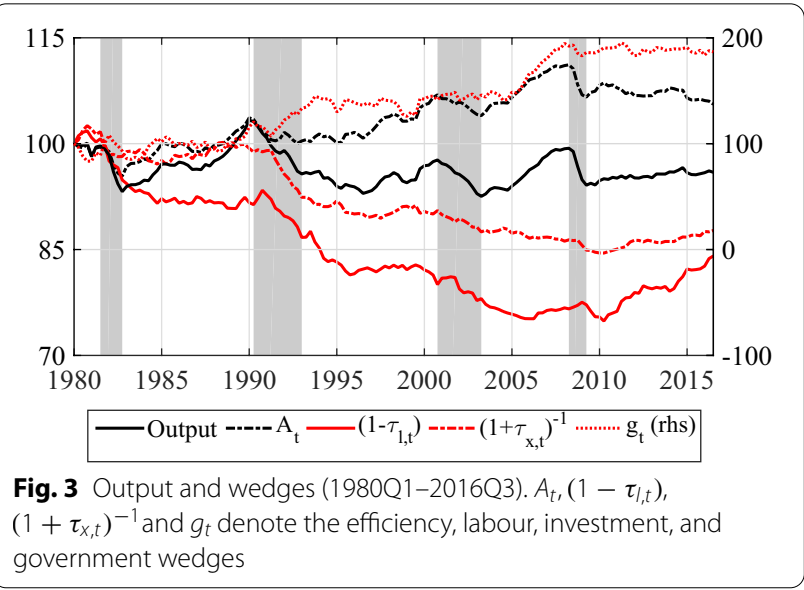

investment wedge and the labour wedge. Furthermore, the labour wedge appears to lag the output by a few quarters. Taking a closer look at the highlighted recession episodes shows that they are all associated with a worsening of both the efficiency and the investment wedge. The labour wedge worsens in the 1981, 1990, and 2001 recessions, while the 2007 recession coincides with an improvement in the labour wedge. The worsening of the labour and investment wedges appears to be considerably larger during the 1990s recession than in any other recession experienced since the 1980s.

Table 2 summarizes the standard deviation of the wedges relative to output $\left(Y_{t}\right)$ as well as correlations of the wedges with our model-consistent measures of output, investment $\left(X_{t}\right)$, and total hours $\left(H_{t}\right)$. The data are HPfiltered. Analogous to the plot, the table shows a strong contemporaneous comovement between the efficiency wedge and output. It also reveals a strong comovement between the investment wedge and investment as well as between the labour wedge and total hours. Regarding the standard deviations to output, the high volatility of the government wedge stands out. The high volatility can be explained by two factors. First, it is driven by net exports, which in our closed-economy model are added to government consumption. Second, high volatility also occurs because our measure of government expenditures includes all statistical errors made in the estimation of quarterly GDP.

\subsection{Role of the wedges in the $1990 \mathrm{~s}$}

In the following, we take a closer look at the role of the efficiency, labour, and investment wedges for our target period, focusing separately on the build-up and burst of the bubble (1987Q1-1992Q4, with the turning point in 1990Q2) and the ensuing stagnation (1993Q1-1996Q4). Our computations are based on the assumption that the 
Table 2 Wedge properties (1980Q1-2016Q3)

\begin{tabular}{|c|c|c|c|c|c|c|c|c|c|c|}
\hline \multirow[t]{2}{*}{$w_{t}$} & \multirow[t]{2}{*}{$\frac{\sigma\left(W_{t}\right)}{\sigma\left(Y_{t}\right)}$} & \multicolumn{3}{|c|}{$\operatorname{Corr}\left(W_{t+k}, Y_{t}\right)$} & \multicolumn{3}{|c|}{$\operatorname{Corr}\left(W_{t+k}, X_{t}\right)$} & \multicolumn{3}{|c|}{$\operatorname{Corr}\left(W_{t+k}, H_{t}\right)$} \\
\hline & & $k=-1$ & $k=0$ & $k=1$ & $k=-1$ & $k=0$ & $k=1$ & $k=-1$ & $k=0$ & $k=1$ \\
\hline Efficiency wedge & 0.71 & 0.87 & 0.93 & 0.73 & 0.66 & 0.67 & 0.56 & 0.67 & 0.54 & 0.38 \\
\hline Government wedge & 3.53 & 0.30 & 0.44 & 0.44 & -0.04 & -0.09 & 0.03 & 0.21 & 0.23 & 0.21 \\
\hline Labour wedge & 0.78 & 0.35 & 0.45 & 0.57 & 0.30 & 0.39 & 0.54 & 0.64 & 0.78 & 0.77 \\
\hline Investment wedge & 0.58 & 0.44 & 0.45 & 0.45 & 0.68 & 0.83 & 0.75 & 0.65 & 0.66 & 0.60 \\
\hline
\end{tabular}

Data is HP-filtered with $\lambda=1600$
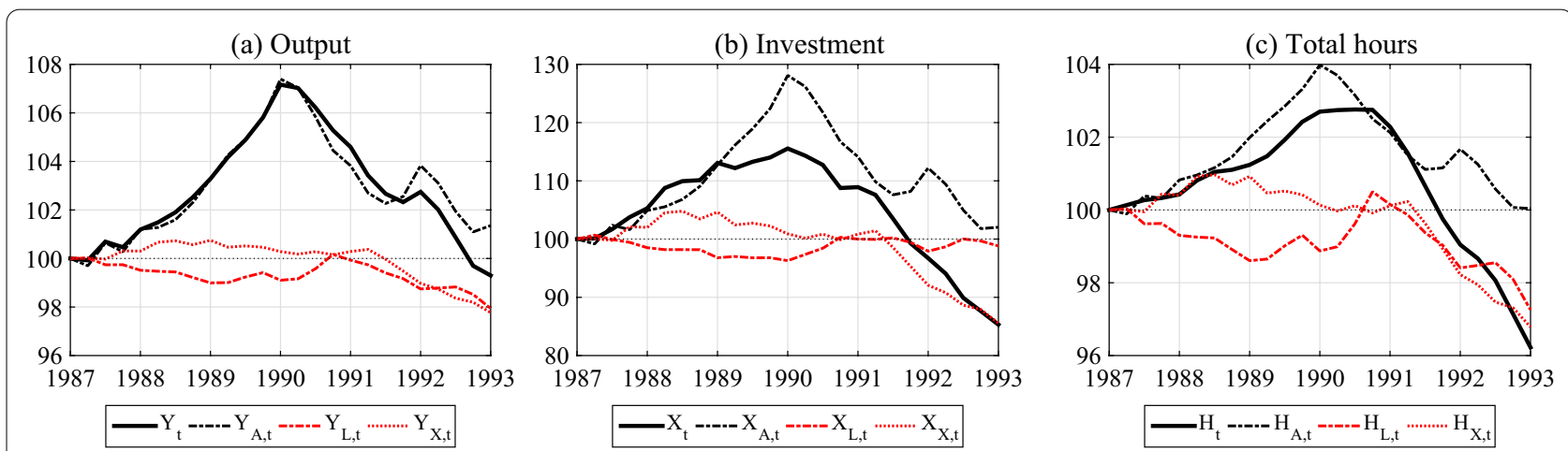

Fig. 4 Aggregates and their wedge-alone components 1987Q1-1993Q1. The subscripts $A, L, X$ denote the efficiency-, labour-, and investment-wedge-alone component of output $Y_{t}$, investment $X_{t}$, or total hours $H_{t}$

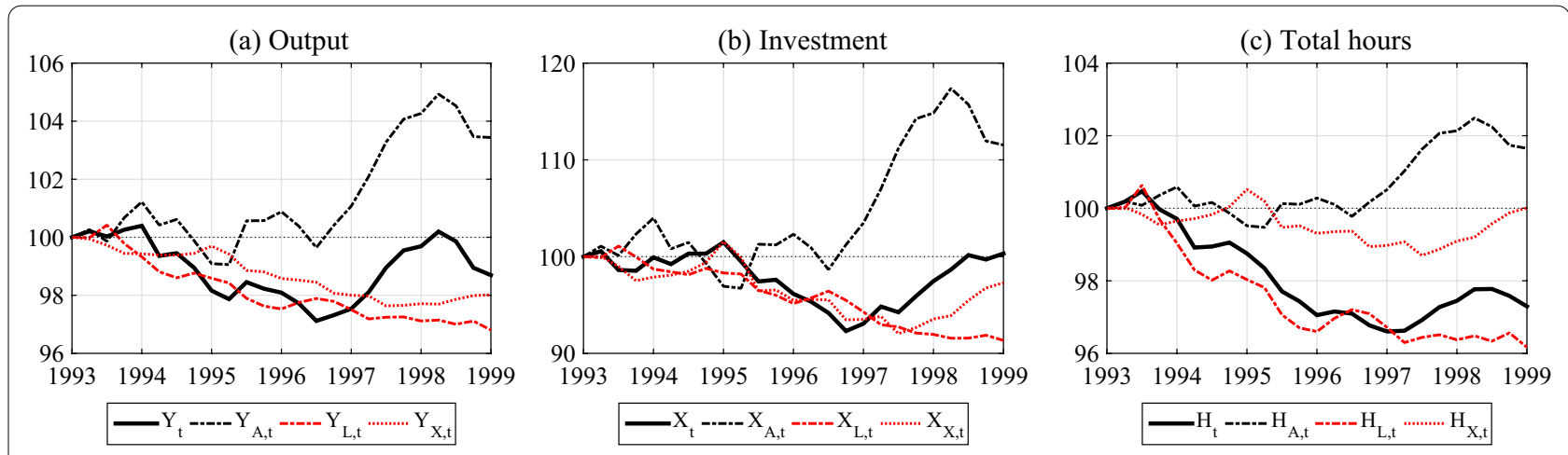

Fig. 5 Aggregates and their wedge-alone components 1993Q1-1999Q1. The subscripts $A, L, X$ denote the efficiency-, labour-, and investment-wedge-alone component of output $Y_{t}$, investment $X_{t}$, or total hours $H_{t}$

capital stock is in steady state in 1987Q1. Figures 4 and 5 summarize our results. In both figures, panel $a$ summarizes the evolution of output (solid black line) together with the model predictions of output if only one wedge is allowed to fluctuate, namely an efficiency-wedgealone component (dashed black), a labour-wedge-alone component (dashed red), or an investment-wedge-alone component (dotted red). Panels $b$ and $c$ repeat the same exercise for investment and aggregate hours, respectively. The way to read the plots is that-focusing, for instance, on panel $a$-the closer a counterfactual experiment is to actual output (the solid black line), the more important that specific wedge is in the evolution of output. The distance between the actual output and each of the different counterfactual lines represents the contribution of the remaining wedges to the evolution of the output.

According to Fig. 4a, the large increase in output in the 1987-1990 period can be attributed almost entirely to improvement in the efficiency wedge. Panels $b$ and $c$ of Fig. 4 show that this improvement in the efficiency 
wedge is also the main driver of the observed boom in investment and the increase in total hours worked. The patterns for the recession phase in Fig. 4 are similar: again it is largely the efficiency wedge that explains the observed output movements, at least at the beginning of the recession. Starting around 1991, the deterioration in the labour and investment wedges led to a deepening of the recession. In 1991 and 1992, the worsening of the labour and investment wedges explains roughly half of the observed decline in output.

Regarding the stagnation phase, Fig. 5 shows that while the efficiency wedge develops roughly in step with output, it is no longer the dominant driver. Instead, the sluggish development observed over the 1993Q1-1996Q4 episode is largely driven by a deterioration in both the investment and labour wedge. The deterioration in these two wedges also acts as a main driver of the evolution of investment. Regarding aggregate hours, Fig. 5c shows that the identified labour wedge closely tracks the evolution of aggregate hours.

Thus far, we have assessed the role of the wedges based on visual inspection. A useful summary statistic that quantifies this assessment is the so called $\Phi$-statistic (see Chari et al., 2007; Brinca et al., 2016). This statistic captures how closely the different counterfactual lines in Figs. 4 and 5 track their underlying variables. More specifically, the $\Phi$-statistic of, say, the efficiency-wedgealone component of output $\left(\Phi_{a}^{Y}\right)$ measures how well the efficiency wedge can explain the fluctuations in output in comparison with the labour, investment, and government wedges. ${ }^{13}$ The $\Phi$-statistic has the useful feature that it always lies between 0 and 1 , with 1 meaning that a certain wedge-alone component perfectly tracks its underlying variable. Table 3 reports the $\Phi$-statistics for different episodes. According to the statistics, the efficiency wedge can explain $99 \%$ of the movements in output during the boom phase 1987Q1-1990Q2 and 77\% of the movements during the bust phase 1990Q3-1992Q4. It also explains more than $50 \%$ of the movements in investment and $40 \%$ of the movements in total hours in the boom and bust phases. For the stagnation phase between 1993Q1-1996Q4, however, the efficiency wedge can account for only $6 \%$ of the movements in output. Ninety per cent of the movements are explained by the labour and investment wedges. The bulk of the movements, $61 \%$, is explained by the labour wedge, while the investment

\footnotetext{
${ }^{13}$ The $\Phi$-statistic is defined as

$$
\Phi_{j}^{q}=\frac{1 / \sum_{t}\left(q_{t}-q_{j, t}\right)^{2}}{\sum_{j}\left(1 / \sum_{t}\left(q_{t}-q_{j, t}\right)^{2}\right)},
$$

where $q_{i, t}$ is the $j$-wedge-alone component of variable $q$ with $j=(A, L, X, G)$ and $q=(Y, X, H)$.
}

\begin{tabular}{|c|c|c|c|c|}
\hline & $\Phi_{A}^{q}$ & $\Phi_{L}^{q}$ & $\Phi_{X}^{q}$ & $\Phi_{G}^{q}$ \\
\hline \multicolumn{5}{|l|}{ Output } \\
\hline 1987Q1-1990Q2 & 0.99 & 0.00 & 0.00 & 0.00 \\
\hline 1990Q3-1992Q4 & 0.77 & 0.08 & 0.11 & 0.04 \\
\hline 1993Q1-1996Q4 & 0.06 & 0.61 & 0.29 & 0.03 \\
\hline \multicolumn{5}{|l|}{ Investment } \\
\hline 1987Q1-1990Q2 & 0.54 & 0.11 & 0.25 & 0.10 \\
\hline 1990Q3-1992Q4 & 0.56 & 0.06 & 0.33 & 0.05 \\
\hline 1993Q1-1996Q4 & 0.04 & 0.24 & 0.69 & 0.03 \\
\hline \multicolumn{5}{|l|}{ Total hours } \\
\hline 1987Q1-1990Q2 & 0.66 & 0.05 & 0.18 & 0.10 \\
\hline 1990Q3-1992Q4 & 0.41 & 0.17 & 0.37 & 0.06 \\
\hline 1993Q1-1996Q4 & 0.06 & 0.80 & 0.10 & 0.04 \\
\hline
\end{tabular}

$\Phi_{j}^{q}$ denotes the $\Phi$-statistics of the $j$-wedge-alone component of aggregate $q$ (output, investment, or total hours). The subscripts $A, L, X, G$ denote the efficiency, labour, investment, and government wedges

wedge accounts for $29 \%$. The labour and investment wedges also account for approximately $90 \%$ of the movements in investment and total hours during the stagnation phase.

The results in Figs. 4 and 5 and Table 3 are depicted in terms of model-consistent (hence detrended) data. Table 4 translates our results into real per capita terms (hence including the trend component). For each episode, the table reports two different values: the numbers in the first block correspond to growth rates over the entire episode studied. For better comparability across episodes, numbers in the second block are annualized. The table highlights the same striking features discussed for the figures, namely that the build-up, recession, and stagnation appear to have different causes. The boom preceding the recession as well as the recession itself is largely driven by the efficiency wedge, while deterioration in the labour and investment wedges plays an important role in the sluggish recovery. In addition to the information contained in the figures, Table 4 also depicts the results for the role played by the government wedge. For all episodes of interest, it adds positively to output growth. However, the government wedge does not play a dominant role in the evolution of output at any time.

The finding that most of the variations in output in the stagnation of the 1990s were driven by the labour and investment wedges is quite particular,-both compared to Switzerland's own historical experience as well as from an international perspective. For comparison, Table 5 reports the $\Phi$-statistics of Swiss output during three episodes: 1980Q1-1986Q4, 1999Q1-2007Q2, and 2005Q1-2013Q2. These episodes include the phases 
Table 4 Decomposition of real output movements (1987Q1-1996Q4)

\begin{tabular}{|c|c|c|c|c|c|c|}
\hline \multirow[t]{2}{*}{ Episode } & \multirow[t]{2}{*}{ Output growth } & \multicolumn{5}{|c|}{ Output components } \\
\hline & & Efficiency & Government & Labour & Investment & Trend \\
\hline Full episode & 7.2 & 1.8 & 3.3 & -4.3 & -4.2 & 10.6 \\
\hline \multicolumn{7}{|l|}{ Episode specific } \\
\hline 1987Q1-1990Q2 & 10.3 & 6.8 & 0.7 & -0.8 & 0.2 & 3.5 \\
\hline 1990Q3-1992Q4 & -3.9 & -4.6 & 1.4 & -1.1 & -2.1 & 2.4 \\
\hline 1993Q1-1996Q4 & 1.4 & 0.4 & 1.0 & -2.2 & -1.9 & 4.1 \\
\hline \multicolumn{7}{|l|}{ Annualized } \\
\hline 1987Q1-1990Q2 & 3.0 & 2.0 & 0.2 & -0.2 & 0.1 & 1.0 \\
\hline 1990Q3-1992Q4 & -1.5 & -1.8 & 0.6 & -0.4 & -0.8 & 1.0 \\
\hline 1993Q1-1996Q4 & 0.3 & 0.1 & 0.3 & -0.6 & -0.5 & 1.0 \\
\hline
\end{tabular}

Numbers in per cent. Output growth measured in real per capita terms

before, during and after the recessions in 1981, 2001, and 2009. According to the table, the efficiency wedge was the most dominant driver in all episodes under consideration, typically accounting for over $50 \%$ of the variation in output. From an international perspective, Brinca (2014) analyses business cycles for a large set of countries and finds that, in general, the efficiency wedge plays the most important role for fluctuations in output. Brinca et al. (2016) broadly confirm these results. ${ }^{14}$ These findings, together with the results reported in Table 5, suggest that the 1990s stagnation was a special episode whose drivers differed considerably from those of most other domestic or foreign historical episodes. Hence, these findings reinforce the need for a more thorough investigation of the causes of the 1990s stagnation.

\subsection{Assessing the explanations of the 1990s stagnation}

The accounting results discussed above give us measures of the role of each wedge in specific episodes. In the following, we use these quantitative results together with additional evidence to assess the different hypotheses for the 1990s stagnation. Importantly, although our decomposition allows for a causal assessment of the wedges, evaluating different theories is a more delicate endeavour. The main difficulty is that there is in principle no unique way of relating the distinct narratives of the 1990s stagnation to detailed models. Our strategy in the following is to turn to prominent theoretical mappings from the literature. This allows us to assess-from the viewpoint of our model and the chosen theoretical mapping-which explanations are quantitatively promising.

Our analysis focuses on the most common explanations of the stagnation. As mentioned, at the time, the policy discussion on the causes of the stagnation evolved

\footnotetext{
14 There are some notable exceptions. For example, Chari et al. (2007) and Brinca et al. (2016) found that the labour wedge played a dominant role in the output movements in the United States.
}

Table 5 -statistics of phases before, during and after Swiss recessions

\begin{tabular}{lcccc}
\hline & $\boldsymbol{\Phi}_{A}^{Y}$ & $\boldsymbol{\Phi}_{L}^{Y}$ & $\boldsymbol{\Phi}_{X}^{Y}$ & $\boldsymbol{\Phi}_{G}^{Y}$ \\
\hline 1980Q1-1986Q4 & & & & \\
1980Q1-1981Q3 (pre-recession) & 0.63 & 0.11 & 0.06 & 0.20 \\
1981Q4-1982Q4 (recession) & 0.97 & 0.01 & 0.01 & 0.01 \\
1983Q3-1986Q4 (follow-up) & 0.83 & 0.03 & 0.04 & 0.10 \\
1999Q1-2007Q2 & & & & \\
1999Q1-2000Q4 (pre-recession) & 0.61 & 0.10 & 0.10 & 0.19 \\
2001Q1-2003Q2 (recession) & 0.75 & 0.11 & 0.10 & 0.04 \\
2003Q3-2007Q2 (follow-up) & 0.50 & 0.11 & 0.14 & 0.25 \\
2005Q1-2013Q2 & & & & \\
2005Q1-2008Q2 (pre-recession) & 0.79 & 0.07 & 0.06 & 0.08 \\
2008Q3-2009Q2 (recession) & 0.90 & 0.03 & 0.04 & 0.03 \\
2009Q3-2013Q2 (follow-up) & 0.35 & 0.32 & 0.18 & 0.14 \\
\hline
\end{tabular}

$\Phi^{q}$ denotes the $\Phi$-statistics of the $j$-wedge-alone component of aggregate $q$ (output, investment, or total hours). The subscripts $A, L, X, G$ denote the efficiency, labour, investment and government wedge

primarily around a slowdown in productivity growth. Of particular concern was a lack of competition in sheltered domestically-oriented sectors (e.g. telecommunications, agriculture, or construction), which was viewed as an important impediment to productivity growth. ${ }^{15}$ More recent explanations of the 1990s stagnation tend to place more emphasis on episode-specific factors. These include a depression in exports as a result of appreciation

\footnotetext{
15 This focus is well documented by Lipp (2012), who provides a detailed analysis of the economic policy of the Swiss government over the 1970-2000 period. It is also reflected in the policy measures that were implemented, which focused on increasing competitiveness by increasing competition. Prominent examples include the accession to the World Trade Organization (WTO) in 1995 and the implementation of a federal law on cartels in 1995. Additionally, illustrative for this overall policy focus are two prominent white papers in the 1990s that called for more deregulation and competition, namely those of Hauser et al. (1991) and (written in reaffirmation of the former) De Pury et al. (1995). Baltensperger (2005) offers an evaluation of the white papers' claims and their implementation.
} 
pressures on the Swiss franc caused by a restrictive monetary policy stance; exacerbated financial frictions caused by the bursting of the housing bubble in the early 1990s; and a (pro-cyclical) increase in fees and social security payments that weakened the incentives to work (Dreher \& Sturm, 2005; Ettlin \& Gaillard, 2001; Kleinewefers Lehner, 2007; Kohli, 2005).

\subsubsection{Taxes}

We start by assessing to what extent the deteriorating labour and investment wedges over the 1993-1996 period are tax-induced. That is, we are interested in the extent to which the two wedges-measured as implicit taxes on labour income and investment expenditure-reflect explicit taxes levied by national and local authorities. ${ }^{16}$ To do so, we introduce four explicit tax rates into the baseline model of Sect. 2.1 and derive the mapping to our standard wedges. Namely, the taxes are the marginal tax rate on labour income $\tilde{\tau}_{l}$, the average consumption tax rate $\tilde{\tau}_{c}$, the average tax rate on investment expenditures $\tilde{\tau}_{x}$, and the marginal tax rate on capital income $\tilde{\tau}_{k}$. The only change to our prototype is in the household's budget constraint. Assuming all tax revenues are transferred back to the household via transfers $\ddot{\Omega}_{t}$, it now becomes:

$$
\begin{aligned}
& \left(1+\tilde{\tau}_{c, t}\right) \ddot{c}_{t}+\left(1+\tilde{\tau}_{x, t}\right) \ddot{x}_{t} \leq\left(1-\tilde{\tau}_{l, t}\right) \ddot{w}_{t} l_{t} \\
& \quad+\left(1-\tilde{\tau}_{k, t}\right) r_{t} \ddot{k}_{t}+\ddot{\Omega}_{t} .
\end{aligned}
$$

Based on (3.1), we can solve for a tax-corrected expression of the labour wedge $\widetilde{L W}$. Note that in the following, we abbreviate the labour wedge with $L W_{t}$ (instead of the previously used $1-\tau_{l, t}$ ) to avoid any confusion with actual taxes levied. We receive: ${ }^{17}$

$$
\psi l_{t}^{\nu}=\widetilde{L W} t \frac{\left(1-\tilde{\tau}_{l, t}\right)}{\left(1+\tilde{\tau}_{c, t}\right)}(1-\alpha) \frac{y_{t}}{c_{t} l_{t}} .
$$

As for the investment wedge, it is not possible based on (3.1) to obtain a formal mapping between the standard investment wedge and the tax-corrected investment wedge. As an approximation, we compare the wedge between the Euler equation's left- and right-hand sides under certainty equivalence of (1) our standard model and (2) a model including measured taxes as specified in

\footnotetext{
${ }^{16}$ In the BCA literature, the terms "implicit tax on labour income" and "implicit tax on investment expenditure" are common synonyms for the labour and investment wedge, respectively. Like the labour and investment wedges, implicit taxes need not only reflect explicit taxes, but may also capture other elements such as frictions or data mismeasurement.

17 Comparing the tax-corrected measure $\widetilde{L W}_{t}$ with the previously obtained labour wedge $L W_{t}$ [Eq. (2.9)] shows that part of $L W_{t}$ indeed represents explicit taxes levied, as $L W_{t}=\frac{1-\tilde{\tau}_{l, t}}{1+\tilde{\tau}_{c t,}} \widetilde{L}{ }_{t}$.
}

(3.1). We refer to the object as the Euler equation wedge, $E W_{t}$, and compare the following two expressions:

$$
\begin{aligned}
\frac{c_{t+1}}{c_{t}}= & E W_{t} \beta(1+\gamma)\left(\alpha \text { fracy }_{t+1} k_{t+1}+(1-\delta)\right), \\
\frac{c_{t+1}}{c_{t}}= & \widetilde{E W} \frac{\beta(1+\gamma)}{\left(1+\tau_{\tilde{x}, t}\right)}\left(\left(1-\tilde{\tau}_{k, t+1}\right) \alpha \frac{y_{t+1}}{k_{t+1}}\right. \\
& \left.+\left(1+\tilde{\tau}_{x, t+1}\right)(1-\delta)\right) .
\end{aligned}
$$

Tax data are obtained from McDaniel (2007). Her database covers average Swiss tax rates on consumption, investment, labour, and capital over the 1950-2012 period. ${ }^{18}$ We linearly interpolate to quarterly frequency. To obtain marginal labour income and capital income tax rates, we multiply (respectively) average labour income and capital income tax rates by 1.6. ${ }^{19}$ The number 1.6 has a different background in both instances. For labour income taxes, it is obtained from a comparison of the ratio between Swiss average and marginal tax rates. ${ }^{20}$ For capital income taxes, we were not able to obtain Swiss data of sufficient quality, and the 1.6 stems from a comparison of US average and marginal capital income tax rates based on McDaniel (2007) and Mendoza et al. (1994). The data are depicted in Fig. 9 in the "Appendix". The figure shows an increase in all four tax series over the 1980-2012 sample, in line with the fall in labour and investment wedges depicted in Fig. 3. When focusing more closely on the 1993-1996 period-the period for which we seek an explanation of the deteriorating labour and investment wedges-the increase in labour income taxes stands out. The increase in labour income taxes mainly reflects the increase in the contribution rates to unemployment insurance from 0.4 to $2 \%$ of wage payments in 1993, and to 3\% in 1995 (Steiger, 2007). For the other taxes, most of the changes occurred after $1996 .^{21}$

Figure 6 summarizes the results of our tax decomposition for the 1987Q1-1999Q4 period. The first figure shows the labour wedge $L W_{t}$ (in solid black) together with the tax-corrected labour wedge $\widetilde{L W}_{t}$ (dotted black). The second figure shows the Euler wedge $E W_{t}$ (solid

\footnotetext{
${ }^{18}$ Note that the labour income taxes comprise contributions to the social security system.

19 We use a constant conversion rate of 1.6 as a rough approximation. This approximation is sufficient for our purposes as our quantitative results are not sensitive to the exact factor chosen.

${ }^{20}$ In particular, we consider the effective (total) income tax-schedule at the median income in the four biggest cantons for selected years.

21 There are only a few major tax reforms implemented before 1996 and they are not related to labour income. One notable exception is the introduction of a value-added tax to replace the goods turnover tax in 1995 . However, the change in the tax burden was rather small because the tax rate was only raised from 6.2 to $6.5 \%$. For more details, see, e.g. Hirter et al. (2002).
} 


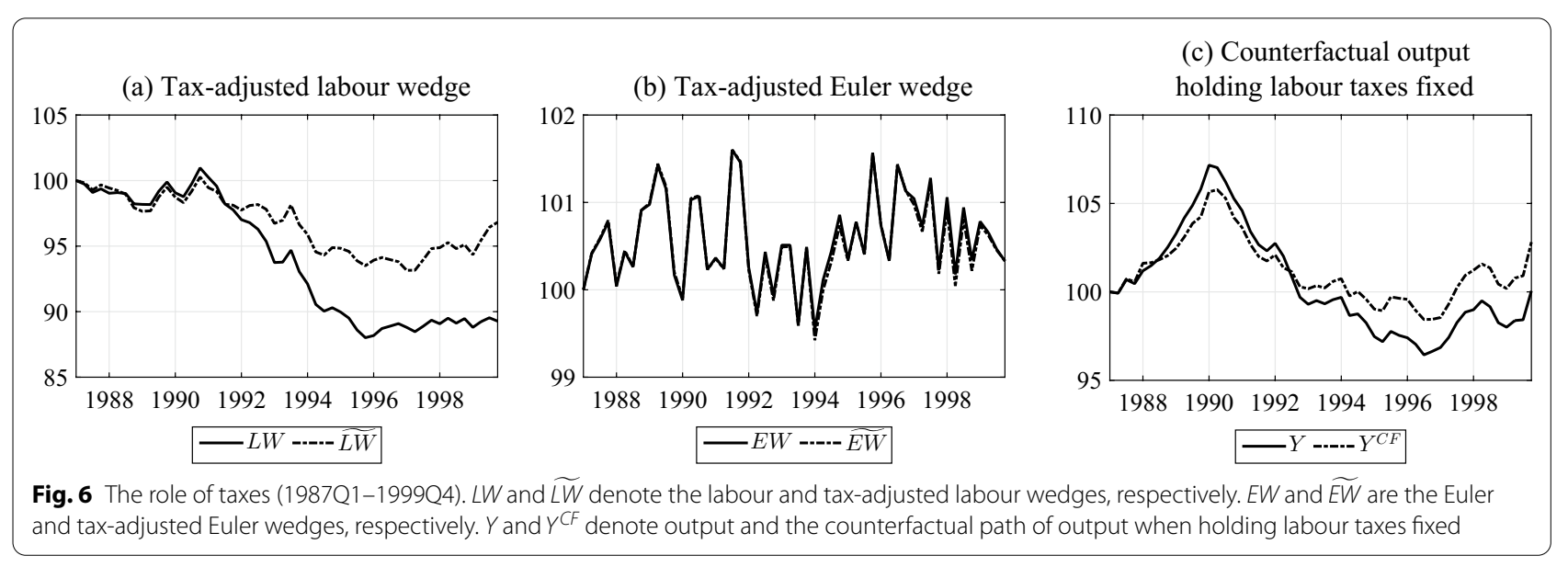

black) together with the tax-corrected Euler wedge $\widetilde{E W}_{t}$ (dotted black). In both cases, the difference between the two lines represents the contribution of taxes. Focusing first on Fig. 6a, the figure shows that approximately $70 \%$ of the observed decline in the labour wedge can be explained by an increase in labour income taxes. ${ }^{22}$ For the 1993Q1-1996Q4 period, the evolution of taxes accounts for approximately $50 \%$ of the deterioration in the labour wedge. To further assess the quantitative importance of these tax changes to output growth, we run a counterfactual exercise assuming the evolution of the labour wedge corresponds to $\widetilde{L W}$ (and all other wedges and the expectations thereof are unchanged, as briefly outlined in Sect. 2.4). The results in terms of our modelconsistent data are depicted in Fig. 6c. Holding labour taxes constant, we estimate total real per capita output growth between 1993Q1-1996Q4 of 1.8\%-which is 2.8 percentage points above the observed growth of $-1 \%$. Our results support the view that increases in fees and social security payments in the 1990 s were an important contributing factor to the 1990s stagnation, an argument brought forward by, e.g. Kohli (2005) and Ettlin and Gaillard (2001). Additionally, note that the increase in payroll taxes occurred along with an extension in unemployment benefits, which potentially explains an even greater share of the observed labour wedge decline; however, in this regard we are left speculating. ${ }^{23}$

Turning to Fig. 6b, the fact that the two lines are merely distinguishable implies that the measured taxes have a

\footnotetext{
${ }^{22}$ We refer only to labour income taxes (without consumption taxes) as variation in consumption taxes plays almost no role in our results in Fig. 6a.

23 See, for instance, Steiger (2007) for a detailed account of the labour market policy changes in the 1990s. According to Steiger (2007), employees' contribution rate to the unemployment system increased from 0.4 to $2 \%$
}

negligible impact on the development of the Euler wedge. Stated differently, according to our tax decomposition, changes in effective investment and capital income taxes cannot account for the observed increase in investment costs in the 1990s.

A potentially critical parameter for assessing the role of labour taxes is the size of the Frisch elasticity of labour supply. To assess the robustness of our results, we repeat our experiments once with a Frisch elasticity twice as high as in the baseline calibration and once with a Frisch elasticity half as high. This is broadly within the usual range considered in robustness analysis in the macroeconomic literature. The results of this robustness analysis are presented in more detail in the "Appendix". The main findings are as follows. Assuming a Frisch elasticity twice as high as in the baseline calibration, we find that changes in labour taxes can explain $75 \%$ of the drop in the labour wedge between 1993Q1-1996Q4. Under this calibration, we obtain a counterfactual real per capita output growth of $0.1 \%$ between 1993Q1-1996Q4 when holding labour taxes constant, as opposed to actual real per capita contraction of $1 \%$. Conversely, when assuming a Frisch elasticity half as high as in the baseline calibration, the development of labour taxes can account for $28 \%$ of the decline in the labour wedge and the counterfactual real per capita output growth when holding labour taxes constant is 2.4\% between 1993Q1-1996Q4. Hence, while different calibrations of the Frisch elasticity lead to quantitative differences, qualitatively, our main results remain valid. For all calibrations of the

\footnotetext{
Footnote 23 (continued)

of wages in 1993 and to $3 \%$ of wages in 1995. Additionally, the duration of unemployment benefit entitlement and replacement rates (how much of the pre-unemployment wage is paid as unemployment benefits) were raised in several steps between 1992 and 2004.
} 


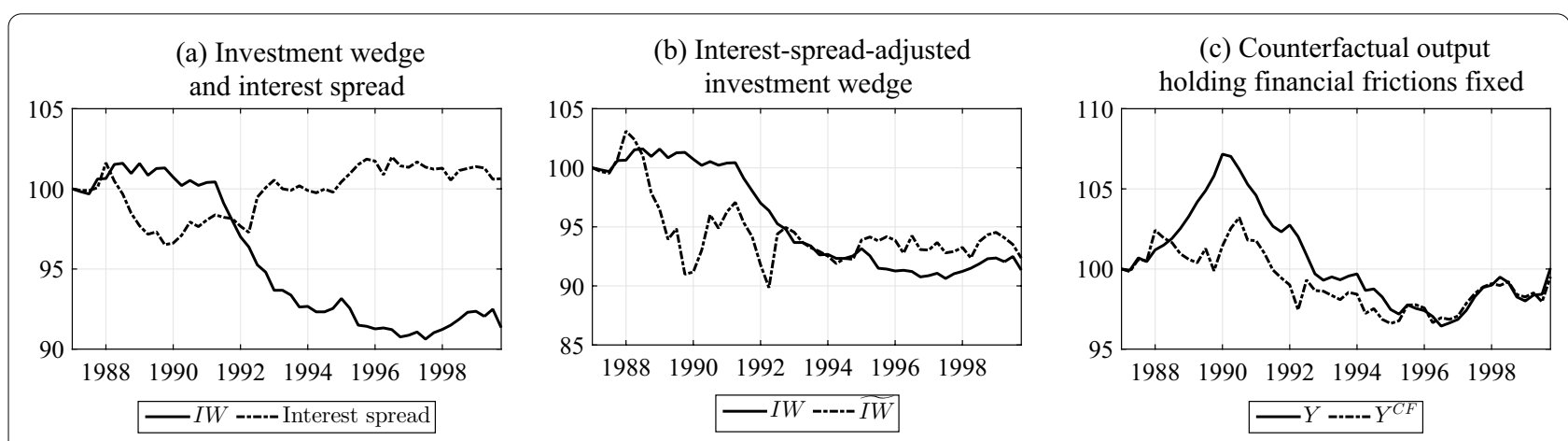

Fig. 7 The role of disruptions in financial intermediation (1987Q1-1999Q4). IW denotes the investment wedge, the interest spread corresponds to the spread between the lending and deposit rates obtained from the IMF International Financial Statistics, and $\widetilde{I W}$ is the interest-spread-adjusted investment wedge. $Y$ is output and $Y^{C F}$ denotes the counterfactual path of output when holding financial frictions fixed

Frisch elasticity considered, we find an important role of changes in labour taxes for the evolution of the labour wedge and output. ${ }^{24}$

\subsubsection{The role of investment frictions}

We now explore the role of investment frictions in the stagnation phase. Similar to our tax assessment, this requires explicitly stating a mapping between a measure of investment frictions and our prototype wedges introduced in Sect. 2.2. However, while taxes readily translate into the budget constraint of our prototype, the difficulty in assessing investment frictions is that there is more leeway in the modelling choices. The following assessment is based on a prominent neoclassical model with costly state verification in the spirit of Carlstrom and Fuerst (1997). ${ }^{25}$ The model specifies a mapping between the lending-deposit spread-which is standardly viewed as an indicator of financial frictions-and the investment wedge. A full overview of the model equations is contained in the "Appendix". In summary, the key difference from our prototype is that agency problems between borrowers and lenders generate a spread between the return on investment and the savings rate. Based on this set-up, we obtain an expression of the investment wedge $I W_{t}$ as a function of the lending-deposit spread $s p r_{t}$, monitoring costs $\mu$, and the distribution of the idiosyncratic risk component of investment projects $F(\omega)$,

\footnotetext{
${ }^{24}$ The Frisch elasticities considered are an order of magnitude larger than the estimates of Martinez et al. (2021), which are based on quasi-experimental evidence from income tax holidays in Switzerland. However, their estimates are not necessarily at odds with our calibration. While Martinez et al. (2021) estimate the "frictional" Frisch elasticity, 1/v in our benchmark model corresponds to the "frictionless" Frisch elasticity. In our BCA approach, frictions are meant to be captured by the wedges.

25 See Lu (2013) for an alternative mapping between lending-deposit spreads and the investment wedge. We prefer Carlstrom and Fuerst (1997) because it allows mapping the investment wedge $I_{t}$ rather than the Euler equation wedge $E W_{t}$ introduced in Sect. 3.3.1.
}

$I W\left(s p r_{t} ; \mu, F(\omega)\right) . \quad$ The financial-frictions-corrected investment wedge $\widetilde{I W}_{t}$ can then be obtained as:

$$
\widetilde{I W}_{t}=\frac{I W_{t}}{I W\left(s p r_{t} ; \mu, F(\omega)\right)} .
$$

Data on the deposit-lending spread are depicted in Fig. $7 \mathrm{a}{ }^{26}$ The evolution of the spread indicates an easing of frictions between 1987 and 1992 and a subsequent sharp increase. To obtain the financial-friction-adjusted investment wedge $\widetilde{I W}_{t}$ from this spread data, we also need to specify the size of monitoring costs $\mu$ and the distribution of the idiosyncratic risk component of investment projects $F(\omega)$. We follow the suggestions of Carlstrom and Fuerst (1997) to work with a range of $0.20-0.36$ and set $\mu=0.25$, where $\omega$ is assumed to follow a log-normal distribution with standard deviation $\sigma_{\omega}=0.207$ and unity mean $\left(\mu_{\omega}=-\frac{\sigma_{\omega}^{2}}{2}\right) .{ }^{27}$ As shown in the "Appendix", our results are robust with respect to different plausible choices of $\mu$ and $\sigma_{\omega}$.

Figure $7 \mathrm{~b}$, c shows our results. In Fig. $7 \mathrm{~b}$, the difference between the financial friction-corrected investment wedge $\widetilde{I W}_{t}$ (black dashed line) and standard investment wedge $I W_{t}$ (solid black line) gives the contribution of financial frictions. The figure shows that financial frictions played an unequal role over the 1987Q1-1999Q4 period. In the boom phase up until 1992, a decrease in financial frictions played a positive role in output, decreasing the cost of investment. The opposite holds after 1992: the increase in financial frictions over the 1993Q1-1996Q4 period explains the entire deterioration of the investment wedge. More precisely, holding financial frictions

\footnotetext{
${ }^{26}$ Data are obtained from the IMF International Financial Statistics. Lending rates are average rates by cantonal banks on variable-rate first mortgages. Deposit rates refer to average rates on three-month deposits with large banks.

27 In the model, monitoring costs are expressed as the share of inputs used for investment projects.
} 
constant, we obtain a $2 \%$ increase in the investment wedge, compared to the actual deterioration of over $6 \%$. To assess the quantitative importance of the identified frictions to output, Fig. 7c shows the results of a counterfactual exercise that sets the investment wedge to $\widetilde{I W}_{t}$ (with results depicted in terms of model-consistent data). Over the entire episode, the role of financial frictions is ambiguous. For 1993Q1-1996Q4 more specifically, holding financial frictions constant and adding trend growth, we obtain real per capita output growth of $4 \%$. For comparison, actual per capita growth was $-1 \%$.

Since the financial friction narrative has not been in the focus of the policy debates, we have looked for further data to corroborate or rebut it. Unfortunately, information on credit conditions in the 1990s is scarce. To our knowledge, besides the deposit-lending spread we use in our analysis, no useful quantitative information on credit conditions is available. Useful surveys, such as the SNB Bank Lending Survey or the KOF Business Tendency Survey, do not date back to the 1990s. However, some research and policy reports provide evidence in favour of the financial friction narrative. For instance, Bodmer (2004) argues that the real estate crisis in the 1990s led to more restrictive bank lending conditions. Also, the quarterly bulletin of the Swiss National Bank (1988) reports that borrowers had greater difficulty in providing the necessary collateral in the 1990s than in the 1980s, which made banks to adopt more cautious lending practices.

At this point, we want to emphasize that our analysis cannot identify the causes for the increase in financial frictions. A plausible driver is the real estate crisis. Both, Swiss National Bank (1988) and Bodmer (2004) mention it as a reason for more cautious bank lending. However, also a restrictive monetary policy stance could have led banks to adopt more cautious lending practices and, hence, exacerbated financial frictions. A deeper investigation of the causes behind the increase in financial frictions is, however, beyond the scope of our paper.

\subsubsection{Depression in net exports}

The role played by a depression in net export can be directly evaluated with the business cycle accounting results that we reported in Sect. 3.2. Through the lens of our model, net exports have not played an important role in observed growth stagnation. The result follows from the wedge decomposition presented in Table 4: Net exports are contained in the government wedge, which according to our results positively added to output growth in the boom, recession, and stagnation that are studied here. ${ }^{28}$ Hence, from the viewpoint of our model, net exports were not a main deterrence to growth. Of course, this finding does not preclude depression in output growth resulting from a restrictive monetary policy stance. However, it suggests that the net export channel of monetary policy was not important as net exports cannot explain the stagnation episode.

\subsubsection{Productivity growth stagnation}

Regarding stagnation in productivity growth, our results are similar. As with the depression in net export narrative, the role played by a stagnation in productivity growth can be directly evaluated with the business cycle accounting results that we reported in Sect. 3.2. According to Fig. 5, the development of the efficiency wedge cannot account for the stagnation phase. The efficiency wedge enters the model equations as a measure of total factor productivity (TFP) or the Solow residual. It is meant to capture the effects of technological and institutional changes and is standardly thought to increase with improved technology, improved competition, or better institutions. According to our results, there is no evidence that TFP fell during the stagnation phase. It remained more or less constant between 1993 and 1996 and then increased by approximately 3\% until 1997Q4. This is not to say that policies to increase competitiveness were unsuccessful or unnecessary. In fact, our results imply that productivity growth after 1996 acted as a main driver of output growth (e.g. Fig. 3). However, Table 4 shows that in the stagnation phase, the efficiency wedge has added positively to growth. Output growth has been deterred mainly by a worsening of the labour and investment wedges, i.e. factors that acted like a tax increase on labour and investment.

The dominant perception (in the Swiss discussion) that stagnation in productivity growth kept the economy from growing may, at least to some extent, stem from the mismeasurement of hours worked (see Sect. 2.3.1). Figure 8 shows the evolution of TFP and the efficiencywedge component of output based on the SNB vs. OECD series of hours worked. The TFP series based on SNB data developed much better in the first half of the stagnation phase. Additionally, the evolution of the efficiencywedge components points to a much more favourable role for productivity when the SNB data are considered. The efficiency-wedge component based on SNB data suggests that TFP has contributed positively to output growth during the entire stagnation phase. In contrast, the efficiencywedge component based on OECD data implies that TFP was a drag on economic growth up to 1995.

\footnotetext{
${ }^{28}$ A modelling justification for adding net exports to the government wedge is given by Chari et al. (2005). They provide a small open-economy model with explicit export-import linkages that is equivalent to a closed-economy model with net exports showing up in government consumption.
} 
(a) Efficiency wedge

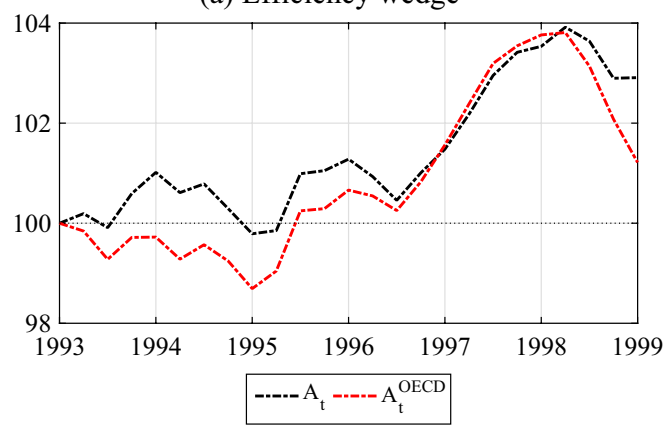

(b) Output and efficiency-wedge component

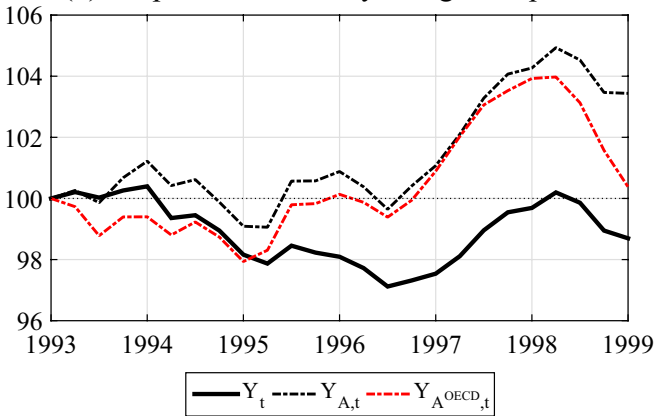

Fig. 8 Hours mismeasurement and productivity. $A_{t}$ and $A_{t}^{O E C D}$ denote the measured efficiency wedge based on the SNB and OECD series of hours worked. $Y_{t}$ denotes output, and $Y_{A, t}$ and $Y_{A O E C D, t}$ are the efficiency-wedge components of output based on the SNB and OECD data for hours worked

\section{Concluding remarks}

We examine the causes of the Swiss stagnation of the 1990s through the lenses of the business cycle accounting framework of Chari et al. (2007). According to our prototype model, the 1990s stagnation is caused by a deterioration of the labour and investment wedge. In contrast, the evolution of the efficiency and government wedge cannot explain the weak growth in the 1990s. Taken at face value, these results provide evidence against the dominant view that the stagnation was caused by a slowdown in productivity growth. They also provide evidence against the narrative that the stagnation was the result of a depression in net exports caused by a too restrictive monetary policy stance. This is not to say that monetary policy did not play an important role per se, but the results suggest that the net export channel of monetary policy cannot account for the weakness in growth.

We find that the increase in labour income taxes and financial frictions in the 1990s is a plausible cause for the stagnation. From the perspective of our prototype model, these factors acted similar to a tax increase on labour and investment. Holding labour income taxes and financial frictions constant, counterfactual annual real output growth is $1.93 \%$ for the years 1993-1996, compared to observed annual growth of $0.35 \%$.

While we find that the increase in labour income taxes and financial frictions is a plausible cause, we would like to emphasize that we cannot-from a technical point of view-rule out other explanations for the stagnation. The reason is that there exists no unique mapping between the different narratives and the wedges. This applies not only to the explanations discussed in the paper, but also to other potentially relevant aspects of the stagnation (such as the unprecedentedly high level of unemployment, insufficient demand or changes in migration). However, what our business cycle accounting exercise clearly shows is that if any of these explanations played an important role, it must have acted like an increase in the cost of labour and investment in a standard neoclassical growth model.

\section{Appendix \\ Defining consistent measurements}

The following provides details on the adjustments to the SECO series on output, consumption, and investment that are needed to make the data consistent with the structure of our model economy. Following Brinca et al. (2016) and Cooley (1995), the data are adjusted in the following way:

(1) To account for working with a closed economy, we include net exports as part of government consumption. A modelling justification is provided by Chari et al. (2005), who show equivalence results between (1) the equilibrium conditions of a small open economy and (2) a closed-economy model that includes net exports as part of government consumption.

(2) We adjust the nominal GDP and its components for sales taxes. Data on the share of GDP accounted for by taxes on goods and services $\left(\tau_{t}\right)$ are from the OECD. We linearly interpolate the annual series to quarterly frequency. We then assume that the sales taxes are levied on consumption and imports, and hence subtract the respective tax shares from our measures of $C_{t}$ and $G_{t}$.

(3) We detrend the series by dividing them by three factors: (1) the implicit GDP price deflator; (2) the quarterly population (obtained by interpolating the annual series using spline methods); and (3) the rate of constant labour augmenting technological progress $\gamma$, computed such that detrended output has mean zero over the sample period. 


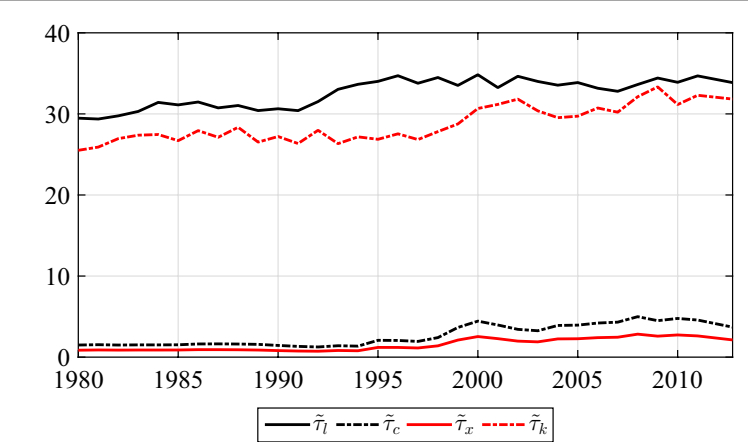

Fig. 9 Evolution of taxes (1980Q1-2012Q4). $\tilde{\tau}_{l}$ is the marginal tax rate on labour, $\tilde{\tau}_{c}$ is the average consumption tax rate, $\tilde{\tau}_{x}$ is the average tax rate on investment, and $\tilde{\tau}_{k}$ is the marginal tax rate on capital income

In principle, we would also want to correct (from a modelling perspective) for the inconsistent treatment by national accounts of consumer durables as consumption rather than investment expenditures. This also implies imputing an estimated flow of services from durables to measured output and consumption. However, with the obtainable data, even a rough classification of consumption expenditures into durables and nondurables is not possible. In principle, the Swiss Federal Statistical Office collects annual data on individual consumption according to purpose, following the classification of the United Nations Statistics Division and Eurostat (so-called COICOP). However, the data are not publicly available, as only results in terms of divisions (not groups) are reported.

\section{Tax data}

\section{Financial frictions model}

We consider a neoclassical model with costly state verification along the lines of Carlstrom and Fuerst (1997) and an exposition thereof in a working-paper version of Chari et al. (2007). The economy is populated by a continuum of households of mass $P_{t}$, a continuum of risk-neutral entrepreneurs of mass $\eta P_{t}$, and a continuum of firms and financial intermediaries of mass 1 . The household objective function and per capita budget constraint are written as follows (using, whenever possible, the same notation as introduced in Sect. 2.1):

$$
\begin{aligned}
& \max \mathbb{E}_{0} \sum_{t=0}^{\infty} \beta^{t}\left\{\left[\log \ddot{c}_{t}-\psi \frac{l_{t}^{1+v}}{1+v}\right] P_{t}\right\}, \\
& \text { s.t. } \ddot{c}_{t}+q_{t}\left[\frac{P_{t+1} \ddot{k}_{h, t+1}}{P_{t}}-(1-\delta) \ddot{k}_{h, t}\right] \leq \ddot{w}_{t} l_{t}+r_{t} \ddot{k}_{h, t} \cdots \\
& \quad+r_{t}^{d}\left[\ddot{w}_{t} l_{t}+r_{t} \ddot{k}_{h, t}-\eta \ddot{T}_{t}^{e}-\ddot{c}_{t}\right]+\ddot{\Omega}_{t}-\eta \ddot{T}_{t}^{e} .
\end{aligned}
$$

In the beginning of the period, households supply labour $l_{t}$ and capital $\ddot{k}_{h, t}$ to firms. After receiving labour and capital income, households pay a transfer $\eta \ddot{T}_{t}^{e}$ to entrepreneurs and purchase consumption goods $\ddot{c}_{t}$. Households can store their remaining income $\left(\ddot{w}_{t} l_{t}+r_{t} \ddot{k}_{h, t}-\eta \ddot{T}_{t}^{e}-\ddot{c}_{t}\right)$ at a bank for a risk-free deposit rate $r_{t}^{d}$. At the end of the period, the market for capital operates. Using the gross-return on saved funds and lump-sum distributed profits $\ddot{\Omega}_{t}$, households buy new capital $\ddot{k}_{h, t+1}-(1-\delta) \ddot{k}_{h, t}$ at a price $\ddot{q}_{t}$. Table 6 in the "Appendix" contains a more complete overview of the timing of events (Fig. 9).

Firms combine the capital of households $\ddot{K}_{h, t}$, capital of entrepreneurs $\eta \ddot{K}_{e, t}$, and labour supplied by households $L_{t}$ to produce consumption goods $\ddot{Y}_{t}$ based on the technology $\ddot{Y}_{t}=A_{t} \ddot{K}_{t}^{\alpha}\left(Z_{t} L_{t}\right)^{1-\alpha}$, where $\ddot{K}_{t} \equiv \ddot{K}_{h, t}+\eta \ddot{K}_{e, t}$. In terms of $\ddot{K}_{t}$, the firm problem is unchanged compared to our prototype of Sect. 2.1.

By comparison to our prototype, the two novel actors are entrepreneurs and financial intermediaries. We jointly specify their problem, as it is closely related. Each entrepreneur $j$ transforms $\ddot{i}_{t}^{j}$ units of consumption goods into $\omega_{t}^{j} \ddot{i}_{t}^{j}$ capital goods. $\omega$ is iid across entrepreneurs and time, with density $\phi$ and c.d.f. $\Phi$. To finance investment $\dddot{i}_{t}^{j}$, entrepreneurs use their net worth $\ddot{a}_{t}^{j}$ and loans obtained from financial intermediaries at the lending rate $\left(1+r_{k, t}{ }^{j}\right)$. Entrepreneur $j$ 's net worth is composed of rental income on capital holdings, the transfer from households and the value of undepreciated capital, i.e. $\ddot{a}_{t}^{j}=\ddot{T}_{t}^{e}+\ddot{k}_{e, t}^{j}\left[r_{t}+q_{t}(1-\delta)\right]$. The transfer $\ddot{T}_{t}^{e}$ ensures that the entrepreneurs who defaulted in the last period can continue to operate.

Financial intermediaries channel funds from households to entrepreneurs. By providing funds to infinitely many entrepreneurs, intermediaries are able to diversify entrepreneurs' idiosyncratic risks and offer households a safe rate $r_{t}^{d}$ on deposits. To introduce agency problems, we assume that the realization of $\omega$ is private information to the entrepreneur. $\omega$ can be observed only by the intermediary at cost $\mu \ddot{i}_{t}^{j}$. This asymmetric information set-up creates a moral hazard problem as entrepreneurs have an incentive to misreport $\omega^{j}$ in the absence of monitoring. As in Carlstrom and Fuerst (1997), we assume that entrepreneurs can enter only into within-period deterministic contracts that are agreed upon before $\omega$ realizes. Townsend (1979) has shown that under such conditions, the optimal contract takes the form of a risky debt contract. Entrepreneur $j$ borrows $\ddot{i}_{t}^{j}-\ddot{a}_{t}^{j}$ consumption goods and agrees to repay $\left(1+r_{k, t}^{j}\right)\left(\ddot{i}_{t}^{j}-\ddot{a}_{t}^{j}\right)$ capital goods. If entrepreneur $j$ is not able to repay, i.e. if $\omega^{j} \ddot{i}_{t}^{j}<\left(1+r_{k, t}^{j}\right)\left(\ddot{i}_{t}^{j}-\ddot{a}_{t}^{j}\right) \equiv \bar{\omega}^{j} \ddot{i}_{t}^{j}$, intermediaries monitor and seize all returns $\omega^{j} i_{t}^{j}$ from the project. Under the contract scheme specified above, entrepreneurs' and financial intermediaries' expected income can be written, respectively, as: 
Table 6 The timing of events in a period

\begin{tabular}{ll}
\hline 1. & Aggregate shocks realize \\
3. & Households and entrepreneurs rent capital and labour to firms. Firms produce consumption goods \\
4. & Households and entrepreneurs receive wage and capital rental payments \\
5. & Households consume part of their income and store the remainder either via bank deposits or at home \\
6. & Firms use their net worth to obtain loans from financial intermediaries to finance their capital creation projects \\
7. & The idiosyncratic productivity shock $\omega$ of each entrepreneur is realized. Entrepreneurs sell the newly created \\
& Households obtain lump-sum transfers $\ddot{\Omega}_{t}$ and the gross return on deposits and buy capital goods. The non- \\
defaulting entrepreneurs make their consumption-saving decisions
\end{tabular}

$$
\begin{aligned}
q_{t} \ddot{i}_{t}^{j} & {\left[\int_{\bar{\omega}_{t}}^{\infty}\left(\omega_{t}-\bar{\omega}_{t}\right) \phi(\omega) d \omega\right] \equiv q_{t} \ddot{i}_{t} f\left(\bar{\omega}_{t}\right), } \\
q_{t} \ddot{i}_{t}^{j} & {\left[\left(1-\Phi\left(\bar{\omega}_{t}\right)\right) \bar{\omega}_{t}+\int_{0}^{\bar{\omega}_{t}}\left(\omega_{t}-\mu\right) \phi(\omega) d \omega\right] } \\
& \equiv q_{t} \ddot{i} t g\left(\bar{\omega}_{t}\right) .
\end{aligned}
$$

All economic rents generated by the contract are assumed to flow to the entrepreneur. The contract that maximizes the entrepreneur's expected income subject to the participation constraint of financial intermediaries is given by the solution to the problem:

$$
\begin{aligned}
& \max _{\ddot{i}_{t}^{\prime}, \bar{\omega}_{t}} \& q_{t} \ddot{i}_{t}^{j} f\left(\bar{\omega}_{t}\right), \\
& \text { s.t. \& } \& q_{t} \ddot{i}_{t}^{j} g\left(\bar{\omega}_{t}\right) \geq\left(1+r_{t}^{d}\right)\left(\ddot{i}_{t}^{j}-\ddot{a}_{t}^{j}\right) .
\end{aligned}
$$

The assumption that all rents flow to entrepreneurs implies that at optimum, the lending rate is minimized, which is the case for $r_{t}^{d}=0$. Combining the FOCs yields:

$$
q_{t} f\left(\bar{\omega}_{t}^{j}\right)+\frac{f^{\prime}\left(\bar{\omega}_{t}^{j}\right)}{g^{\prime}\left(\bar{\omega}_{t}^{j}\right)}\left[1-q_{t} g\left(\bar{\omega}_{t}^{j}\right)\right]=0,
$$

which implies the same $\bar{\omega}_{t}$ for all entrepreneurs, independent of the level of net worth. As the participation constraint holds with equality $\left(\ddot{i}_{t}^{j}=\frac{\ddot{a}_{t}^{j}}{1-q_{t} g\left(\bar{\omega}_{t}\right)}\right)$, the expected income of an entrepreneur with net worth $\ddot{a}_{t}^{j}$ is equal to

$$
q_{t} \ddot{i}_{t}^{j} f\left(\bar{\omega}_{t}\right)=\frac{\ddot{a}_{t}^{j} q_{t} f\left(\bar{\omega}_{t}\right)}{1-q_{t} \bar{\omega}_{t}} .
$$

Since $\ddot{i}_{t}^{j}$ is linear in $\ddot{a}_{t}^{j}$, both aggregate $\ddot{i}_{t}$ and the aggregate income of entrepreneurs are linear in aggregate net worth $\ddot{a}_{t}$. Overall, the after-capital production budget constraint of entrepreneurs can be written as

$$
\ddot{c}_{e, t}^{j}+q_{t} \frac{P_{t+1}}{P_{t}} \ddot{k}_{e, t+1}^{j}=\ddot{a}_{t}^{j} \frac{q_{t} f\left(\bar{\omega}_{t}\right)}{1-q_{t} \bar{\omega}_{t}} .
$$

Aggregating over all entrepreneurs, the aggregate law of motion of entrepreneurial capital can be written as

$$
\begin{aligned}
\ddot{c}_{e, t} & +q_{t} \frac{P_{t+1}}{P_{t}} \ddot{k}_{e, t+1} \\
& =\left(\ddot{T}_{t}^{e}+\ddot{k}_{e, t}\left[r_{t}+q_{t}(1-\delta)\right]\right) \frac{q_{t} f\left(\bar{\omega}_{t}\right)}{1-q_{t} \bar{\omega}_{t}} .
\end{aligned}
$$

Finally, for completeness, we specify the entrepreneurs' objective function, which is given by

$$
\left.\mathbb{E}_{0} \sum_{t=0}^{\infty}(\beta \gamma)\right)^{t} \ddot{c}_{e, t},
$$

with $\gamma \in(0,1)$. The assumption that entrepreneurs discount the future at a higher rate than that of consumers is needed because the return on entrepreneurial savings is larger than the size of household savings. In the steady state, the return on household savings will be exactly $1 / \beta$. If entrepreneurs had the same discount rate as households, they would continue accumulating capital until they become completely self-financed $\left(\ddot{i}_{t}=\ddot{a}_{t}\right)$. Carlstrom and Fuerst (1997) set $1 / \gamma=q f(\bar{\omega}) /(1-q f(\bar{\omega}))$, such that the steady-state return on internal funds of entrepreneurs is exactly equalized. Entrepreneurs maximize their objective function subject to the budget constraint given above.

To summarize the model, the list of general equilibrium equations is:

$$
\begin{aligned}
& y_{t}=A_{t} k_{t}^{\alpha} l_{t}^{1-\alpha}, \\
& \psi\left(l_{t}\right)^{\nu}=(1-\alpha) \frac{y_{t} / c_{t}}{l_{t}}, \Rightarrow\left(1-\tau_{l, t}\right)=1,
\end{aligned}
$$




$$
\begin{aligned}
\frac{q_{t}}{c_{t}} & =\beta(1+\gamma) \mathbb{E}_{t}\left[\frac{1}{c_{t+1}}\left(\alpha \frac{y_{t+1}}{k_{t+1}}+q_{t+1}(1-\delta)\right)\right], \\
\left(1+\gamma_{n}\right)(1+\gamma) k_{t+1} & =(1-\delta) k_{t}+\underbrace{\eta i_{t}\left[1-\Phi\left(\omega_{t}\right) \mu\right]}_{\equiv x_{t}} \\
& = \\
y_{t} & =c_{t}+\eta c_{e, t}+\eta i_{t} .
\end{aligned}
$$

In (4.9), we use $x_{t}$ to denote the sum of all entrepreneurial investments net of the resources spent for monitoring. The detailed model with investment frictions is equivalent to our prototype model with the following investment and government expenditure wedges:

$$
\begin{aligned}
& I W_{t}=\left(\mathbf{1}+\boldsymbol{\tau}_{\boldsymbol{x}, \boldsymbol{t}}\right)=q_{t}, \\
& g_{t}=\eta c_{e, t}+x_{t} \frac{\Phi\left(\bar{\omega}_{t}\right) \mu}{1-\Phi\left(\bar{\omega}_{t}\right) \mu} .
\end{aligned}
$$

For our purposes, what matters is the mapping between the investment wedge $I W_{t}$ and the lending-deposit spread $q_{t}\left(1+r_{t}^{k}\right)$. In particular, using the threshold definition for $\bar{\omega}_{t}$ and the fact that the participation constraint of intermediaries holds with equality, we obtain the following relationship between $\bar{\omega}_{t}$ and the interest spread $q_{t}\left(1+r_{t}^{k}\right) / 1$ :

$$
q_{t}\left(1+r^{k}\right)=\frac{\bar{\omega}_{t}}{g\left(\bar{\omega}_{t}\right)} .
$$

According to the model, $q_{t}\left(1+r^{k}\right)$ can never drop below 1 , as households always have an outside option with zero interest. We normalize the data accordingly. Conditions (4.1) and (4.12) define a theoretical mapping between the lending-deposit spread $q_{t}\left(1+r_{t}^{k}\right)$ and the investment wedge $I W_{t}$ that depends only on the monitoring costs $\mu$ and the distribution of $\omega$,

$$
q_{t}=I W\left(q_{t}\left(1+r_{t}^{k}\right) ; \mu, F(\omega)\right) .
$$

\section{Robustness}

\section{The role of the Frisch elasticity for the BCA exercise}

In the following, we discuss the robustness of our main BCA results for alternative values of the Frisch elasticity. We consider a twice and a half as high Frisch elasticity as in the baseline calibration, i.e. $v=0.5$ and $v=2$. This is broadly within the usual range considered in robustness analyses in the macroeconomic literature.

Properties of the wedges over the 1980-2016 period. Figures 10 and 11 show the evolution of detrended output (solid black line) along with the evolution of the efficiency

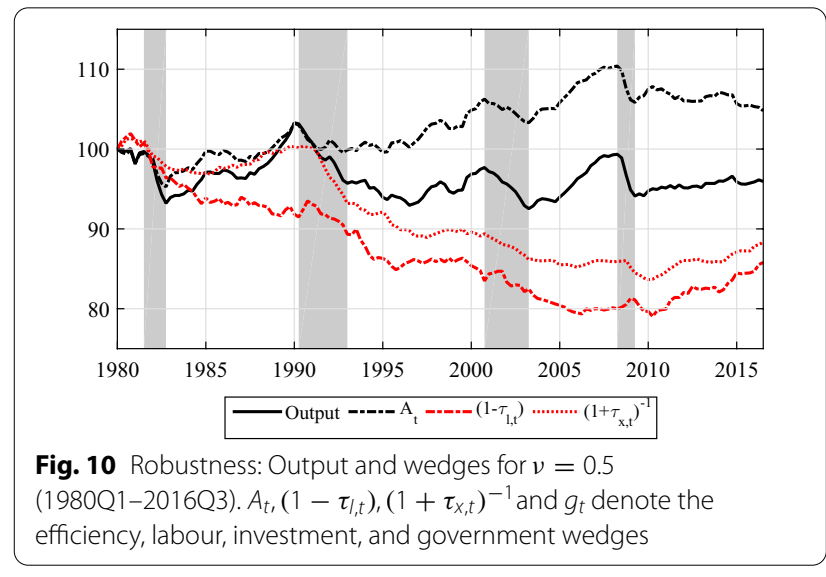

(dashed black), labour (dashed red), and investment (dotted red) wedges for the 1980Q1-2016Q3 period. Tables 7 and 8 summarize the standard deviation of the wedges relative to output $\left(Y_{t}\right)$ and the correlations of the wedges with our model-consistent measures of output, investment $\left(X_{t}\right)$ and total hours $\left(H_{t}\right)$. The results show that changes in $v$ have a small impact on the historical evolution of wedges and wedge' properties in terms of business cycle moments. The main effect is on the properties of the identified labour wedge. The larger the $v$, the more volatile the identified labour wedge is relative to output. Additionally, the identified labour wedge is more strongly correlated with output, investment, and labour when the Frisch elasticity of labour is lower (i.e. for a larger v). Overall, the properties of the identified wedges are broadly similar for the different values of $v$.

Role of the wedges in the 1990s. Figures 12,13, 14 and 15 summarize the role of the different wedges for the buildup and burst of the bubble (1987Q1-1992Q4) and for the ensuing stagnation (1993Q1-1996Q4) for different values of $v$. In all figures, panel a summarizes the evolution of output (solid black line) together with the model predictions of output if only one wedge is allowed to fluctuate, namely an efficiency-wedge-alone component (dashed black), labour-wedge-alone component (dashed red), or an investment-wedge-alone component (dotted red). Panels b and c repeat the same exercise for investment and aggregate hours, respectively. According to the figures, the role of wedges does not change considerably for either $v=0.5$ or $v=2$. In each case, (i) the efficiency wedge plays the dominant role in the boom-phase in the 1987-1990 period and (ii) worsening of the labour and investment wedges contributes considerably to the downturn during the 1991-1992 period and drives sluggish development during 1993Q1-1996Q4. 


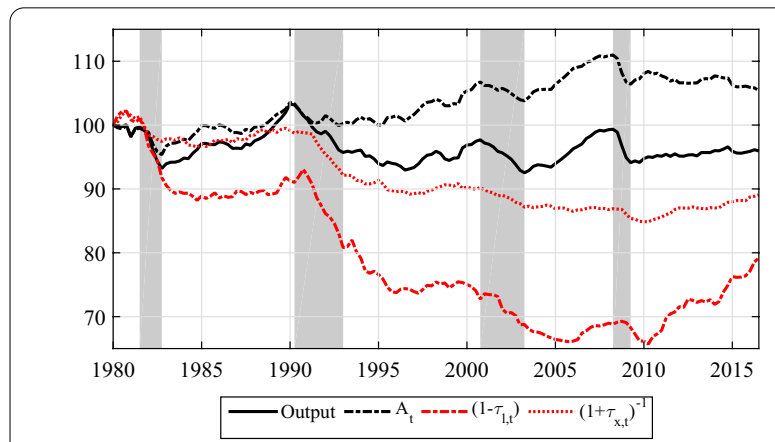

Fig. 11 Robustness: Output and wedges for $v=2(1980 Q 1-2016 Q 3)$ $A_{t},\left(1-\tau_{l, t}\right),\left(1+\tau_{x, t}\right)^{-1}$ and $g_{t}$ denote the efficiency, labour, investment, and government wedges

To quantify the role of the wedges, Tables 9 and 10 report the wedges' contributions to output growth. The starkest differences are in the role of the labour wedge for the bust phase and in the role of the investment wedge for the stagnation phase. The larger the $v$, the more important the labour wedge is (and so the less important the investment wedge is). Overall, the quantitative differences are moderate. Our results on the role of wedges for the 1990s stagnation presented in the main body of the paper (Sect. 3.2) appear robust to changes in $v$.
Assessing the explanations: The role of taxes. Figures 16 and 17 repeat our assessment of the role of taxes for the 1990s stagnation from Sect. 3.3.1 for two alternative values of $v$. Again, panel a shows the labour wedge $L W_{t}$ (in solid black) together with the tax-corrected labour wedge $\widetilde{L W}_{t}$ (dotted black). Panel b shows the Euler wedge $E W_{t}$ (solid black) together with the tax-corrected Euler wedge $\widetilde{E W}_{t}$ (dotted black). In both panels, the difference between the two lines represents the contribution of taxes. Panel c depicts the counterfactual path of output when holding labour taxes fixed. Overall, our results show that the value of $v$ matters for the quantitative assessment of the contribution of taxes. For $v=0.5$, approximately $75 \%$ of the drop in the labour wedge between 1993Q1-1996Q4 can be explained by changes in labour taxes, as opposed to $28 \%$ for $v=2$. Holding labour taxes constant and assuming $v=0.5$, we estimate real per capita output growth between 1993Q1-1996Q4 of $0.12 \%$, as opposed to actual real per capita output contraction of $1 \%$. For $v=2$, the equivalent counterfactual real per capita output growth is $2.38 \%$. While the quantitative results differ depending on the exact value of the Frisch elasticity, they all point towards an important role played by changes in labour taxes for the evolution of the labour wedge and output in the 1990s.

Assessing the explanations: The role of investment frictions. Figures 18 and 19 repeat our assessment of the role of investment frictions from Sect. 3.3.2 for $v=0.5$ and

Table 7 Robustness: Wedge properties for $v=0.5$ (1980Q1-2016Q3)

\begin{tabular}{|c|c|c|c|c|c|c|c|c|c|c|}
\hline \multirow[t]{2}{*}{$w_{t}$} & \multirow[t]{2}{*}{$\frac{\sigma\left(W_{t}\right)}{\sigma\left(Y_{t}\right)}$} & \multicolumn{3}{|c|}{$\operatorname{Corr}\left(W_{t+k}, Y_{t}\right)$} & \multicolumn{3}{|c|}{$\operatorname{Corr}\left(W_{t+k}, X_{t}\right)$} & \multicolumn{3}{|c|}{$\operatorname{Corr}\left(W_{t+k}, H_{t}\right)$} \\
\hline & & $k=-1$ & $k=0$ & $k=1$ & $k=-1$ & $k=0$ & $k=1$ & $k=-1$ & $k=0$ & $k=-1$ \\
\hline Efficiency wedge & 0.71 & 0.87 & 0.93 & 0.73 & 0.66 & 0.67 & 0.56 & 0.67 & 0.54 & 0.38 \\
\hline Government wedge & 3.53 & 0.30 & 0.44 & 0.44 & -0.04 & -0.09 & 0.03 & 0.21 & 0.23 & 0.21 \\
\hline Labour wedge & 0.59 & 0.14 & 0.20 & 0.32 & 0.10 & 0.16 & 0.32 & 0.40 & 0.55 & 0.57 \\
\hline Investment wedge & 0.58 & 0.57 & 0.66 & 0.72 & 0.70 & 0.87 & 0.87 & 0.85 & 0.92 & 0.87 \\
\hline
\end{tabular}

Data are HP-filtered with $\lambda=1600$

Table 8 Robustness: Wedge properties for $v=2$ (1980Q1-2016Q3)

\begin{tabular}{|c|c|c|c|c|c|c|c|c|c|c|}
\hline \multirow[t]{2}{*}{$W_{t}$} & \multirow[t]{2}{*}{$\frac{\sigma\left(W_{t}\right)}{\sigma\left(Y_{t}\right)}$} & \multicolumn{3}{|c|}{$\operatorname{Corr}\left(W_{t+k}, Y_{t}\right)$} & \multicolumn{3}{|c|}{$\operatorname{Corr}\left(W_{t+k}, X_{t}\right)$} & \multicolumn{3}{|c|}{$\operatorname{Corr}\left(W_{t+k}, H_{t}\right)$} \\
\hline & & $k=-1$ & $k=0$ & $k=1$ & $k=-1$ & $k=0$ & $k=1$ & $k=-1$ & $k=0$ & $k=1$ \\
\hline Efficiency wedge & 0.71 & 0.87 & 0.93 & 0.73 & 0.66 & 0.67 & 0.56 & 0.67 & 0.54 & 0.38 \\
\hline Government wedge & 3.53 & 0.30 & 0.44 & 0.44 & -0.04 & -0.09 & 0.03 & 0.21 & 0.23 & 0.21 \\
\hline Labour wedge & 1.32 & 0.52 & 0.64 & 0.74 & 0.49 & 0.60 & 0.71 & 0.81 & 0.93 & 0.89 \\
\hline Investment wedge & 0.57 & 0.57 & 0.61 & 0.62 & 0.74 & 0.88 & 0.83 & 0.79 & 0.82 & 0.75 \\
\hline
\end{tabular}

Data are HP-filtered with $\lambda=1600$ 


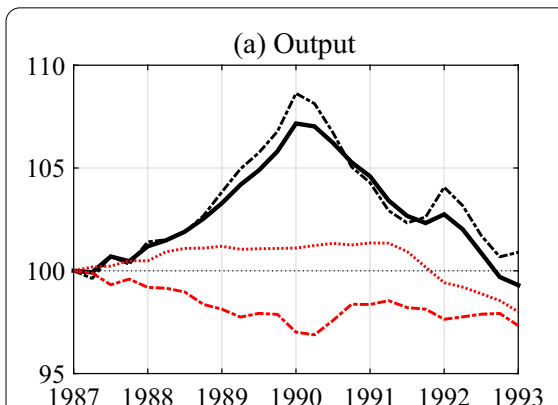

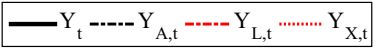

(b) Investment

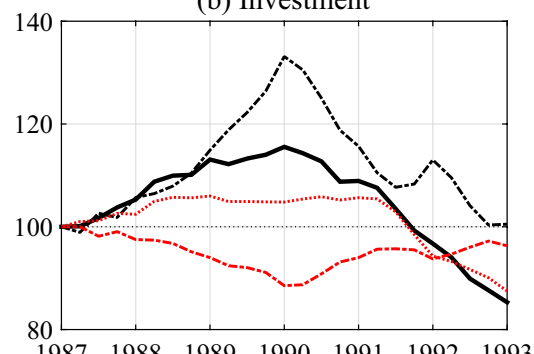

$-\mathrm{X}_{\mathrm{t}} \cdots \mathrm{X}_{\mathrm{A}, \mathrm{t}} \cdots \mathrm{X}_{\mathrm{L}, \mathrm{t}} \cdots \cdots \cdots \cdot \mathrm{X}_{\mathrm{X}, \mathrm{t}}$ (c) Total hours

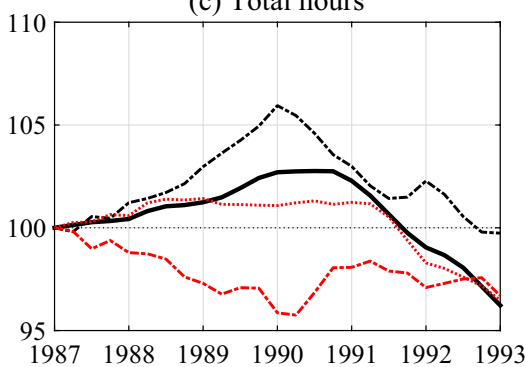

$-\mathrm{H}_{\mathrm{t}} \cdots \cdots \mathrm{H}_{\mathrm{A}, \mathrm{t}} \cdots---\mathrm{H}_{\mathrm{L}, \mathrm{t}} \cdots \cdots \cdots \cdots \cdot \mathrm{H}_{\mathrm{X}, \mathrm{t}}$

Fig. 12 Robustness: The 1987Q1-1993Q1 period for $v=0.5$. The subscripts $A, L, X$ denote the efficiency-, labour-, and investment-wedge-alone components of output $Y_{t}$, investment $X_{t}$, or total hours $H_{t}$
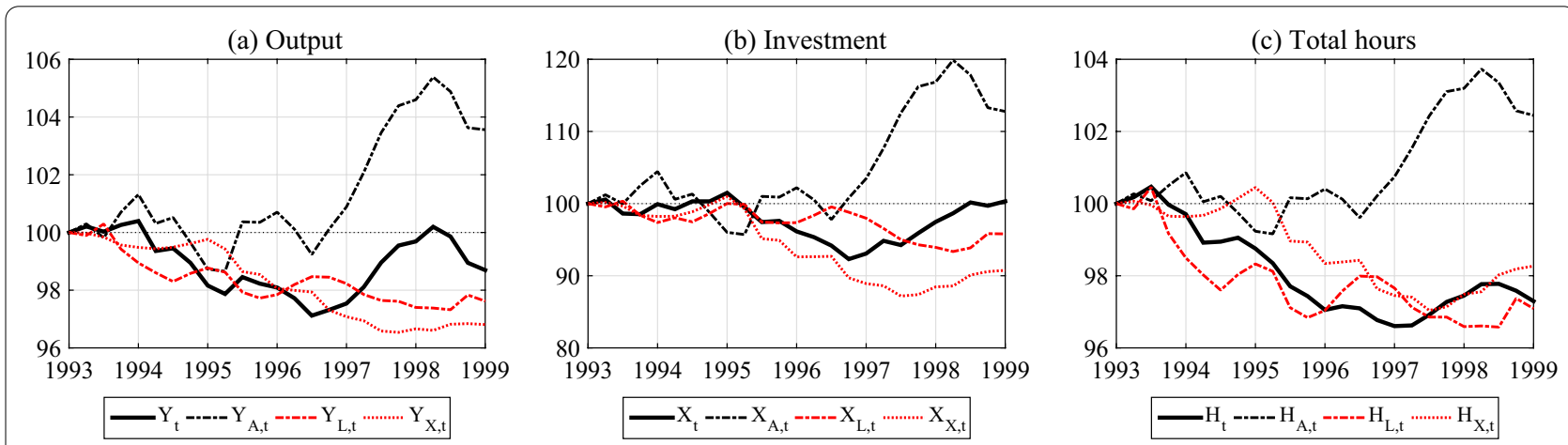

Fig. 13 Robustness: The 1993Q1-1999Q1 period for $v=0.5$. The subscripts $A, L, X$ denote the efficiency-, labour-, and investment-wedge-alone components of output $Y_{t}$, investment $X_{t}$, or total hours $H_{t}$
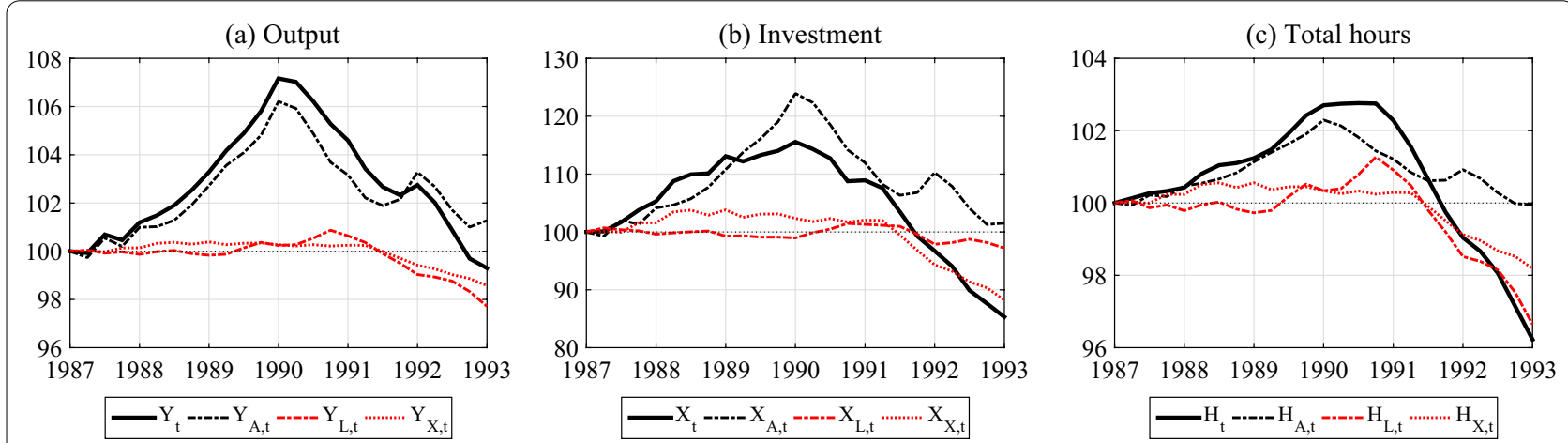

Fig. 14 Robustness: The 1987Q1-1993Q1 period for $v=2$. The subscripts $A, L, X$ denote the efficiency-, labour-, and investment-wedge-alone components of output $Y_{t}$, investment $X_{t}$, or total hours $H_{t}$

$v=2$. As in Fig. 7, panel a depicts the investment wedge $I W_{t}$ (in solid black) together with the lending-deposit spread (dotted black). Panel b shows the investment wedge $I W_{t}$ (in solid black) together with the financialfriction-corrected labour wedge $\widetilde{I W}_{t}$ (dotted black). The difference between the two lines represents the contribution of investment frictions. Panel c depicts the counterfactual path of output when holding financial frictions constant. According to our results, for both $v=0.5$ and $v=2$, changes in investment frictions can explain the 

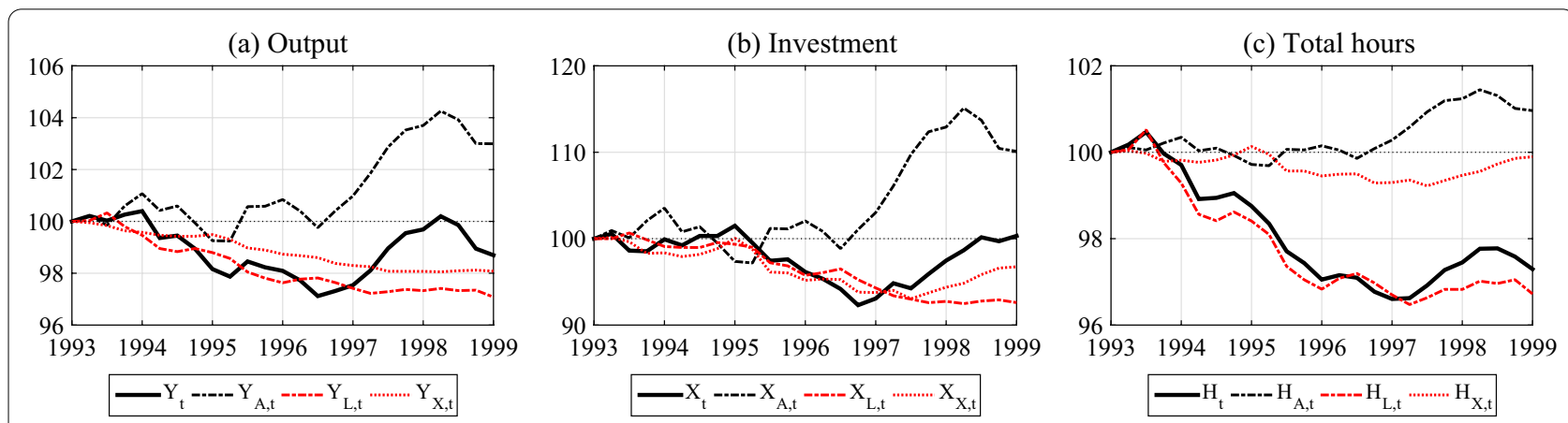

Fig. 15 Robustness: The 1993Q1-1999Q1 period for $v=2$. The subscripts $A, L, X$ denote the efficiency-, labour-, and investment-wedge-alone components of output $Y_{t}$, investment $X_{t}$, or total hours $H_{t}$

Table 9 Robustness: Decomposition of real output movements for $v=0.5$ (1987Q1-1997Q4)

\begin{tabular}{|c|c|c|c|c|c|c|}
\hline \multirow[t]{2}{*}{ Episode } & \multirow[t]{2}{*}{ Output growth } & \multicolumn{5}{|c|}{ Output components } \\
\hline & & Efficiency & Government & Labour & Investment & Trend \\
\hline Full episode & 10.5 & 5.2 & 4.3 & -5.1 & -5.5 & 11.7 \\
\hline \multicolumn{7}{|l|}{ Episode specific } \\
\hline 1987Q1-1990Q2 & 10.3 & 7.8 & 0.9 & -3.2 & 1.2 & 3.5 \\
\hline 1990Q3-1992Q4 & -3.9 & -5.8 & 1.9 & 0.3 & -2.8 & 2.4 \\
\hline 1993Q1-1997Q4 & 4.7 & 4.3 & 1.2 & -2.4 & -3.5 & 5.2 \\
\hline \multicolumn{7}{|l|}{ Annualized } \\
\hline 1987Q1-1990Q2 & 3.0 & 2.3 & 0.3 & -0.9 & 0.4 & 1.0 \\
\hline 1990Q3-1992Q4 & -1.5 & -2.3 & 0.8 & 0.1 & -1.1 & 1.0 \\
\hline 1993Q1-1997Q4 & 0.9 & 0.9 & 0.2 & -0.5 & -0.7 & 1.0 \\
\hline
\end{tabular}

Numbers in per cent. Output growth measured in real per capita terms

Table 10 Robustness: Decomposition of real output movements for $v=2$ (1987Q1-1997Q4)

\begin{tabular}{|c|c|c|c|c|c|c|}
\hline \multirow[t]{2}{*}{ Episode } & \multirow[t]{2}{*}{ Output growth } & \multicolumn{5}{|c|}{ Output components } \\
\hline & & Efficiency & Government & Labour & Investment & Trend \\
\hline Full episode & 10.5 & 4.7 & 2.5 & -5.0 & -3.4 & 11.7 \\
\hline \multicolumn{7}{|l|}{ Episode specific } \\
\hline 1987Q1-1990Q2 & 10.3 & 5.8 & 0.5 & 0.3 & 0.2 & 3.5 \\
\hline 1990Q3-1992Q4 & -3.9 & -3.8 & 1.1 & -2.2 & -1.4 & 2.4 \\
\hline 1993Q1-1997Q4 & 4.7 & 3.5 & 0.7 & -2.7 & -1.9 & 5.2 \\
\hline \multicolumn{7}{|l|}{ Annualized } \\
\hline 1987Q1-1990Q2 & 3.0 & 1.7 & 0.2 & 0.1 & 0.1 & 1.0 \\
\hline 1990Q3-1992Q4 & -1.5 & -1.5 & 0.4 & -0.9 & -0.6 & 1.0 \\
\hline 1993Q1-1997Q4 & 0.9 & 0.7 & 0.1 & -0.5 & -0.4 & 1.0 \\
\hline
\end{tabular}

Numbers in per cent. Output growth measured in real per capita terms

entire deterioration of the investment wedge. Furthermore, the value of $v$ implies only small differences for counterfactual output. Keeping financial frictions fixed and assuming $v=0.5$, we obtain real per capita output growth between 1993Q1-1996Q4 of 5.39\%. For $v=2$, the same number is $4.26 \%$. Hence both qualitatively and quantitatively, the role of investment frictions presented in Sect. 3.3.2 is robust to reasonable changes in $v$. 

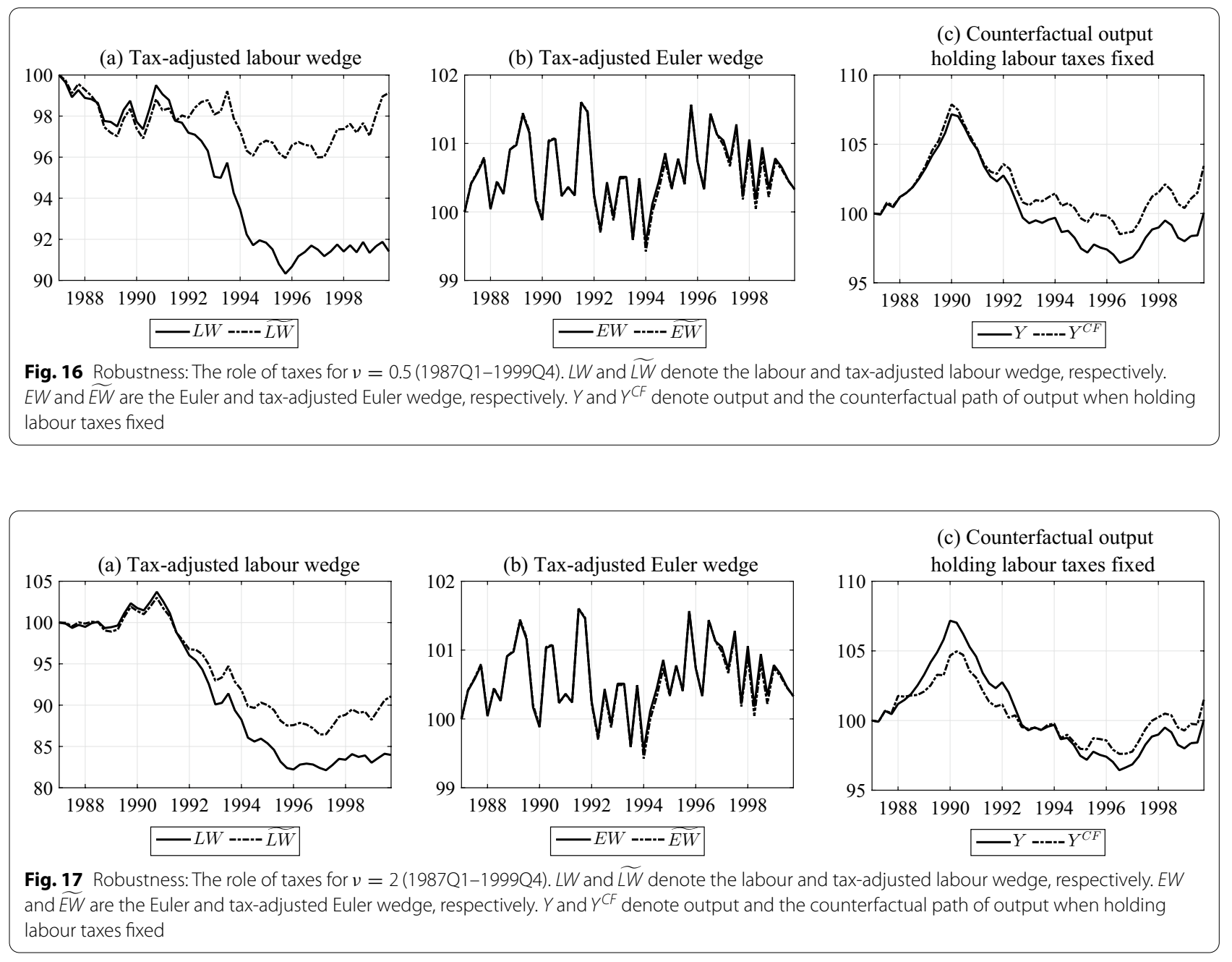

Assessing the explanations: Productivity growth stagnation. Figures 20 and 21 depict the evolution of the efficiency wedge and the utilization-adjusted efficiency wedge for the calibration with $v=0.5$ and $v=2$. We find no large differences. As concluded in Sect. 3.3.3, we find no evidence for a slowdown productivity growth during the stagnation phase.

\section{Robustness of the investment wedge to lending-deposit spread relation}

In the following, we repeat our assessment of the role of investment frictions from Sect. 3.3.2 for alternative calibrations of the two parameters pertaining to the model's financial market. We choose alternative values for monitoring costs $(\mu=0.2,0.36)$ and for the standard deviation of the idiosyncratic risk component of investment projects $\left(\sigma_{\omega}=0.1,0.3\right)$ within the range considered reasonable by Carlstrom and Fuerst (1997). Figures 22, 23, 24 and 25 depict the results. In particular, panel a shows the investment wedge $I W_{t}$ (in solid black) together with the lending-deposit spread (dotted black). Panel b depicts the investment wedge $I W_{t}$ (in solid black) together with the financial-friction-corrected labour wedge $\widetilde{I W}_{t}$ (dotted black). In both panels, the difference between the two lines represents the contribution of investment frictions. Panel c depicts the counterfactual path of output when holding financial frictions constant. In all cases, investment frictions can explain the entire deterioration of the investment wedge between 1992Q1 and 1996Q4. Additionally, there are no major differences in counterfactual real per capita output growth. Holding financial frictions constant and assuming $\mu=0.2$, $\mu=0.36, \sigma_{\omega}=0.1$, or $\sigma_{\omega}=0.3$, we obtain real per capita output growth between 1993Q1-1996Q4 of 3.40\%, $5.25 \%, 4.37 \%$, and $3.04 \%$. Overall, the role of investment frictions is very similar among all different calibrations. 


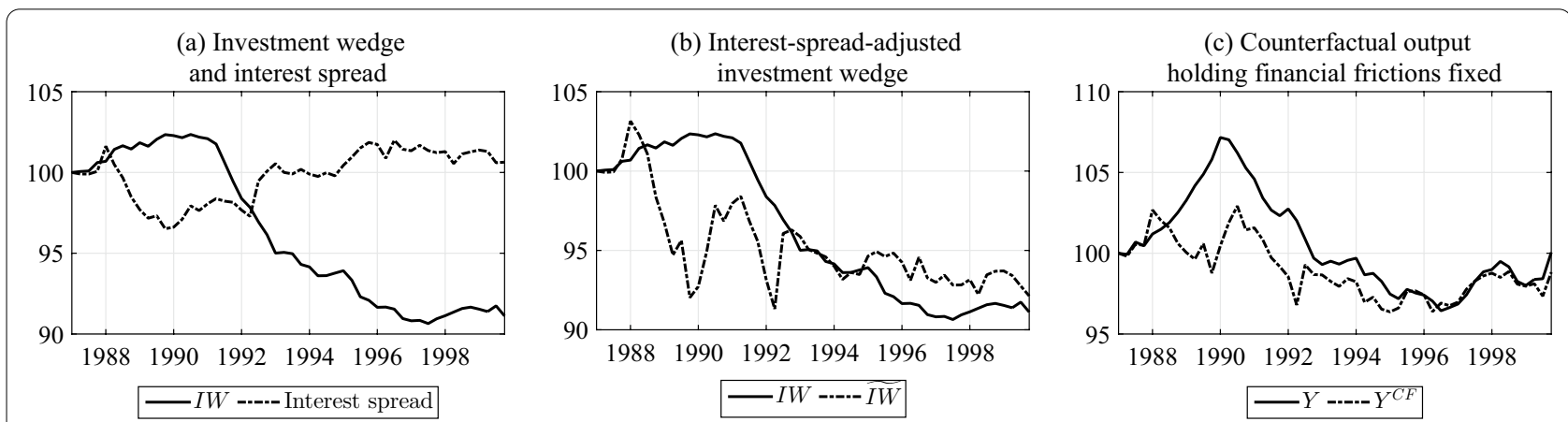

Fig. 18 Robustness: The role of disruptions in financial intermediation for $v=0.5$ (1987Q1-1999Q4). IW denotes the investment wedge, the interest spread corresponds to the spread between the lending and deposit rates obtained from the IMF International Financial Statistics, and IW is the interest-spread-adjusted investment wedge. $Y$ is output and $Y^{C F}$ denotes the counterfactual path of output when holding financial frictions fixed

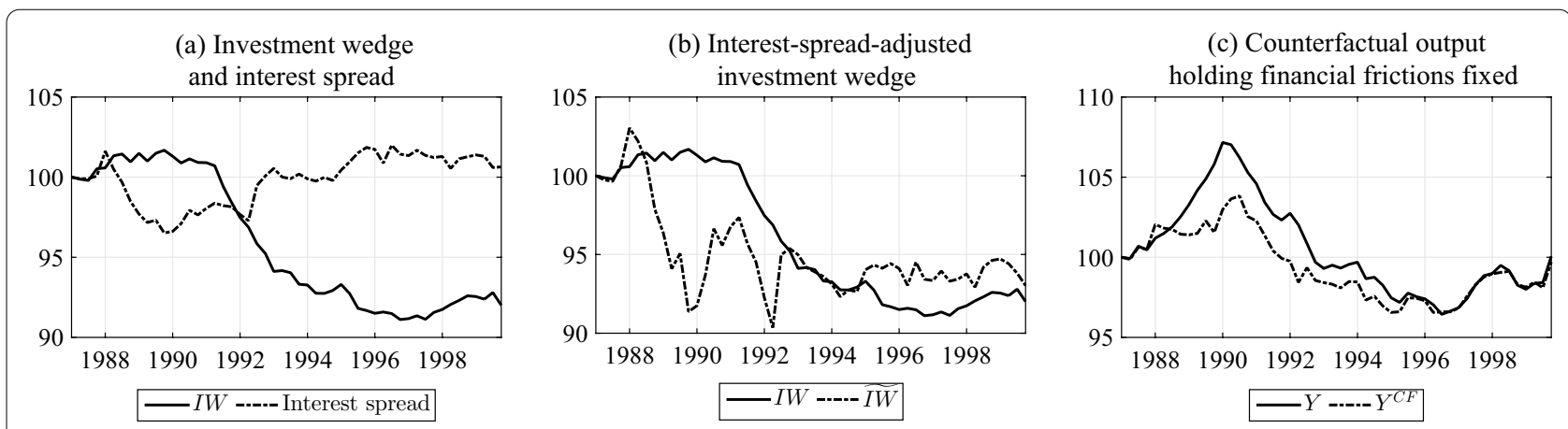

Fig. 19 Robustness: The role of disruptions in financial intermediation for $v=2$ (1987Q1-1999Q4). IW denotes the investment wedge, the interest spread corresponds to the spread between the lending and deposit rates obtained from the IMF International Financial Statistics, and IW is the interest-spread-adjusted investment wedge. $Y$ is output and $Y^{C F}$ denotes the counterfactual path of output when holding financial frictions fixed
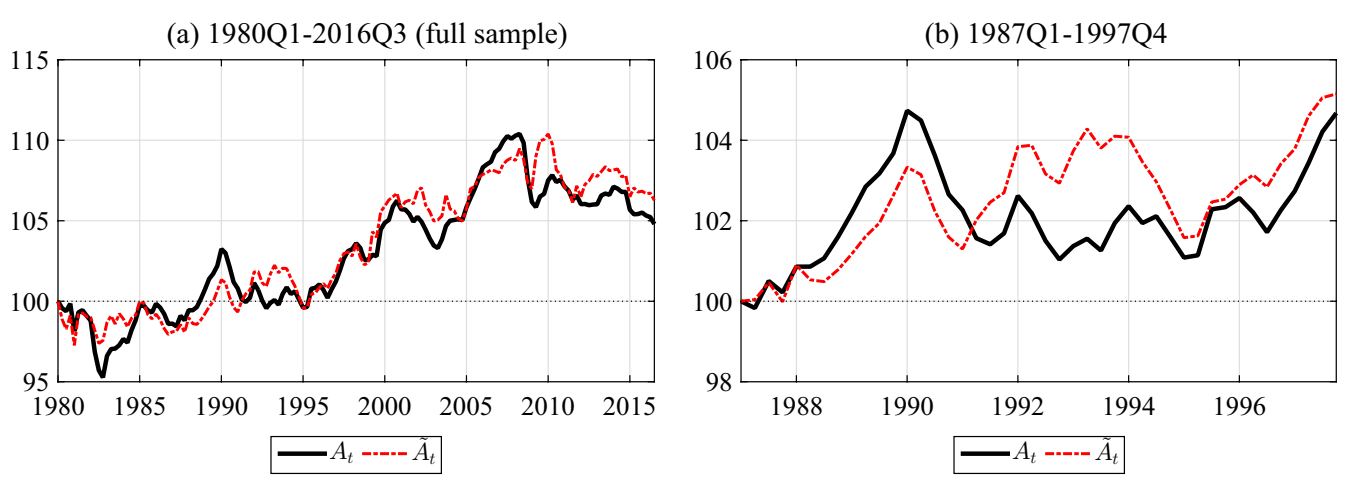

Fig. 20 Robustness: Productivity and utilization-adjusted productivity for $v=0.5$. $A_{t}$ and $\tilde{A}_{t}$ are the efficiency and the utilization-adjusted efficiency wedge, respectively 

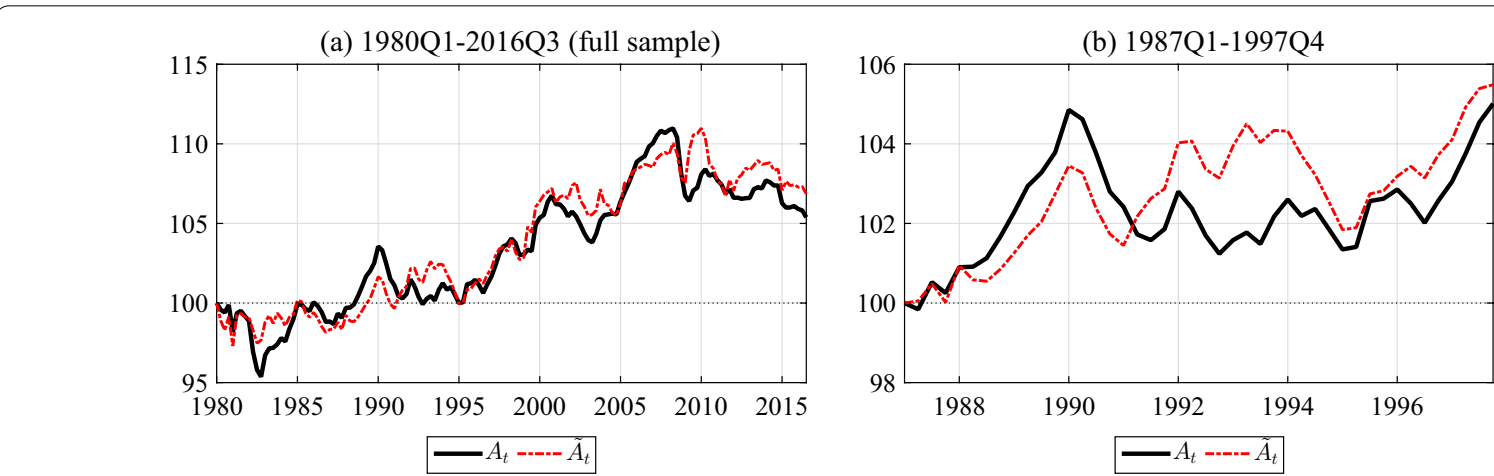

Fig. 21 Robustness: Productivity and utilization-adjusted productivity for $v=2$. $A_{t}$ and $\tilde{A}_{t}$ are the efficiency and the utilization-adjusted efficiency wedge, respectively
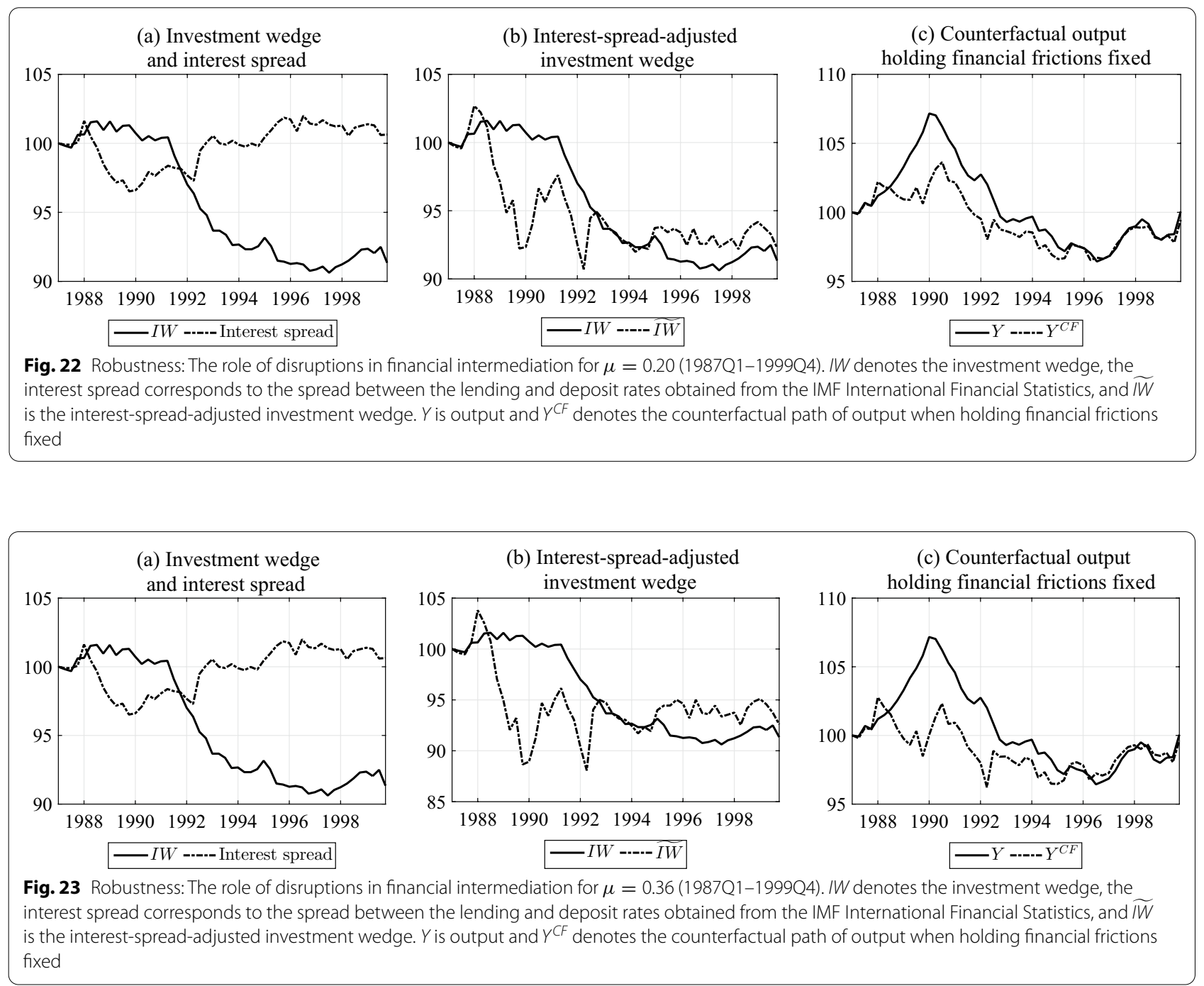


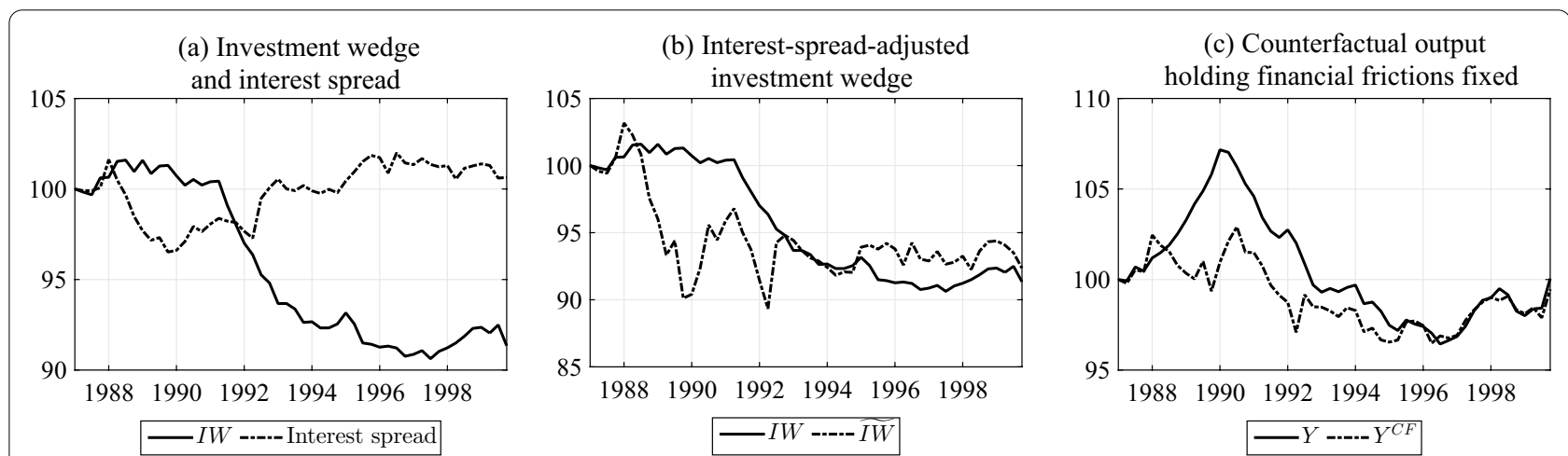

Fig. 24 Robustness: The role of disruptions in financial intermediation for $\sigma_{\omega}=0.10$ (1987Q1-1999Q4). IW denotes the investment wedge, the interest spread corresponds to the spread between the lending and deposit rates obtained from the IMF International Financial Statistics, and IW is the interest-spread-adjusted investment wedge. $Y$ is output and $Y^{C F}$ denotes the counterfactual path of output when holding financial frictions fixed

(a) Investment wedge Counterfactual output
Fig. 25 Robustness: The role of disruptions in financial intermediation for $\sigma_{\omega}=0.30$ (1987Q1-1999Q4). IW denotes the investment wedge, the
interest spread corresponds to the spread between the lending and deposit rates obtained from the IMF International Financial Statistics, and $\mathbb{I W}$
is the interest-spread-adjusted investment wedge. $Y$ is output and $Y$ CF denotes the counterfactual path of output when holding financial frictions
fixed

\section{Abbreviations}

BCA: Business cycles accounting; EW: Euler equation wedge; GCF: Gross capital formation; GFCF: Gross fixed capital formation; IMF: International Monetary Fund; IW: Investment wedge; LW: Labour wedge; MRS: Marginal rate of substitution; OECD: Organisation for Economic Co-operation and Development; RBC: Real business cycle; SECO: Swiss State Secretariat for Economic Affairs; SNB: Swiss National Bank; TFP: Total factor productivity; WTO: World Trade Organisation.

\section{Acknowledgements}

We wish to thank Aymo Brunetti, Fabrice Collard, Till Ebner, Tim Kehoe, Matthias Lutz, Christian Myohl, Sarah Lein (the editor) and three anonymous referees for helpful discussions and valuable comments. The views, opinions, findings and conclusions or recommendations expressed in this paper are strictly those of the authors. They do not necessarily reflect the views of the Swiss National Bank. The Swiss National Bank takes no responsibility for any errors or omissions in, or for the correctness of, the information contained in this paper

\section{Author's contributions}

Both authors contributed to the data collection, analysis, and writing of the paper. Both authors read and approved the final manuscript.

\section{Funding}

Thomet gratefully acknowledges financial support for this project from the "IMG Stiftung" and the Swiss Study Foundation. However, the IMG Stiftung and the Swiss Study Foundation were not involved in the study design; in the collection, analysis, and interpretation of data; in the writing of the article; and in the decision to submit the article for publication.

\section{Availability of data and materials}

The datasets supporting the conclusion of this article are available as follows: Data on output, consumption, and investment from SECO are available online at https://www.seco.admin.ch/seco/de/home/wirtschaftslage---wirts chaftspolitik/Wirtschaftslage/bip-quartalsschaetzungen-/daten.html. The SNB-constructed quarterly hours series is available from the corresponding author on reasonable request. Tax data from McDaniel (2007) are available online at http://www.caramcdaniel.com. Data on the deposit-lending spread are obtained from the IMF International Financial Statistics and are available online at https://data.imf.org/?sk=4c514d48-b6ba-49ed-8ab9-52b0c1a017 $9 \mathrm{~b}$. Lending rates are average rates by cantonal banks on variable-rate first mortgages. Deposit rates refer to average rates on three-month deposits with large banks. Users of Eikon Datastream may download the data using the mnemonics "SWQ60P..," "SWQ60L..". 


\section{Declarations}

Ethics approval and consent to participate

Not applicable.

\section{Consent for publication}

Not applicable.

\section{Competing interests}

The authors declare that they have no competing interests.

\section{Author details}

${ }^{1}$ Swiss National Bank, Börsenstrasse 15, 8022 Zürich, Switzerland. ${ }^{2}$ Swiss National Bank, Bundesplatz 1, 3003 Bern, Switzerland.

Received: 28 December 2020 Accepted: 5 October 2021

Published online: 22 November 2021

\section{References}

Abrahamsen, Y., Aeppli, R., Atukeren, E., Graff, M., Müller, C., \& Schips, B. (2005). The Swiss disease: Facts and artefacts. A reply to Kehoe and Prescott. Review of Economic Dynamics, 8(3), 749-758.

Adamek, J. (2011). Three essays in applied macroeconomics. Ph.D. Thesis, University of Bern.

Baltensperger, E. (2005). Mut zum Aufbruch: 10 Jahre danach. Orell Füessli Verlag.

Bodmer, F. (2004). Ausmass und Gründe der Wirtschaftskrise der 90er Jahre. WWZ-Forschungsbericht 06/04-c. Resource document. Retrieved April 24, 2021 from http://hdl.handle.net/10419/127493

Brinca, P. (2014). Distortions in the neoclassical growth model: A cross-country analysis. Journal of Economic Dynamics and Control, 47, 1-19.

Brinca, P., Chari, V. V., Kehoe, P. J., \& McGrattan, E. R. (2016). Accounting for business cycles. Handbook of Macroeconomics, 2, 1013-1063.

Carlstrom, C. T., \& Fuerst, T. S. (1997). Agency costs, net worth, and business fluctuations: A computable general equilibrium analysis. The American Economic Review, 87(5), 893-910.

Chari, V. V., Kehoe, P. J., \& McGrattan, E. R. (2005). Sudden stops and output drops. The American Economic Review, 95(2), 381-387.

Chari, V. V., Kehoe, P. J., \& McGrattan, E. R. (2007). Business cycle accounting. Econometrica, 75(3), 781-836.

Cooley, T. F. (1995). Frontiers of business cycle research. Princeton University Press.

De Pury, D., Hauser, H., \& Schmid, B. (1995). Mut zum Aufbruch. Eine wirtschaftspolitische Agenda für die Schweiz: Orell Füessli Verlag.

Dreher, A. \& Sturm, J.-E. (2005). Wachstumsschwäche Schweiz: ein Vergleich mit anderen (kleinen) europäischen Staaten. Diskussionsbeiträge 1 Thurgauer Wirtschaftsinstitut (TWI).

Ettlin, F., \& Gaillard, S. (2001). Die 90er Jahre in der Schweiz: Eine wettbewerbsfähige Wirtschaft braucht eine stabilisierende Geldpolitik. In J. Furrer \& B. Gehrig (Eds.), Aspekte der schweizerischen Wirtschaftspolitik. Rüegger Verlag.

Hauser, H., Schwarz, G., \& Vallender, K. A. (1991). Schweizerische Wirtschaftspolitik im internationalen Wettbewerb: eine ordnungspolitische Analyse. Orell Füessli Verlag.
Hirter, H., Benteli, M., Bernath, M., \& Ehrensperger, E. (2002). Schweizerische Politik 1990 bis 2001. Ein Überblick über die wichtigsten Ereignisse und Entscheidungen. Resource document. Retrieved December 28, 2020 from http://www.anneepolitique.swiss/docu/CHPolitik1990-2001.pdf

Jordà, Ò., Schularick, M., \& Taylor, A. M. (2013). When credit bites back. Journal of Money, Credit and Banking, 45(2), 3-28.

Kehoe, T., \& Prescott, E. C. (2002). Great depressions of the 20th century. Review of Economic Dynamics, 5(1), 1-18.

Kehoe, T. \& Ruhl, K. (2003). Recent great depressions: Aggregate growth in New Zealand and Switzerland, 1973-2000. New Zealand Economic Papers, 37(1), 5-40.

Kehoe, T., \& Ruhl, K. (2005). Is Switzerland in a great depression? Review of Economic Dynamics, 8(3), 759-775.

Klein, P. (2000). Using the generalized Schur form to solve a multivariate linear rational expectations model. Journal of Economic Dynamics and Control, 24(10), 1405-1423.

Kleinewefers Lehner, A. (2007). Die konjunkturelle Entwicklung. Die Schweizerische Nationalbank (pp. 1907-2007). Neue Zürcher Zeitung Verlag.

Kohli, U. (2004). Real GDP, real domestic income, and terms-of-trade changes. Journal of International Economics, 62(1), 83-106.

Kohli, U. (2005). Switzerland's growth challenge. Speech at the Osec Podium "Domestic Trade versus Foreign Trade", December 7th.

Lampart, D. (2006). Handlungsspielräume und -restriktionen der Schweizer Konjunkturpolitik in der langen Stangation der 1990er Jahre: Eine modellbasierte Evaluation. Ph.D. Thesis, University of Zurich.

Lipp, S. (2012). Standort Schweiz im Umbruch. Neue Zürcher Zeitung Verlag

Lu, S.-S. (2013). The role of capital market efficiency in long-term growth: A quantitative exploration. Journal of Macroeconomics, 36, 161-174.

Martinez, I. Z., Saez, E., \& Siegenthaler, M. (2021). Intertemporal labor supply substitution? Evidence from the swiss income tax holidays. American Economic Review, 111(2), 506-46.

McDaniel, C. (2007). Average tax rates on consumption, investment, labor and capital in the OECD 1950-2003. Resource document. Retrieved January 16, 2017 from http://www.caramcdaniel.com

Mendoza, E. G., Razin, A., \& Tesar, L. L. (1994). Effective tax rates in macroeconomics: Cross-country estimates of tax rates on factor incomes and consumption. Journal of Monetary Economics, 34(3), 297-323.

Siegenthaler, M. (2015). Has Switzerland really been marked by low productivity growth? Hours worked and labor productivity in Switzerland in a longrun perspective. Review of Income and Wealth, 61(2), 353-372.

Steiger, H. M. (2007). Labour market policy in Switzerland: Institutions, design, effects. Ph.D. Thesis, University of St. Gallen.

Swiss Federal Banking Commission. (1997). EBK-Jahresbericht 1997. Swiss Financial Market Supervisory Authority FINMA: Technical report.

Swiss National Bank. (1998). Quartalsheft 1/1998. Swiss National Bank: Technical report.

Townsend, R. M. (1979). Optimal contracts and competitive markets with costly state verification. Journal of Economic Theory, 21(2), 265-293.

Weder, J. (2018). Als die SNB die Kontrolle verlor. Neue Zürcher Zeitung.

\section{Submit your manuscript to a SpringerOpen ${ }^{\oplus}$ journal and benefit from:}

- Convenient online submission

- Rigorous peer review

- Open access: articles freely available online

- High visibility within the field

Retaining the copyright to your article

Submit your next manuscript at springeropen.com 